\title{
PIV and Rotational Raman-Based Temperature Measurements for CFD Validation in a Single Injector Cooling Flow
}

\author{
Mark P. Wernet and Nicholas J Georgiadis \\ NASA Glenn Research Center, Cleveland, OH, 44135 \\ Randy J. Locke \\ Vantage Partners LLC, Cleveland, $\mathrm{OH}, 44135$
}

\begin{abstract}
Film cooling is used in a wide variety of engineering applications for protection of surfaces from hot or combusting gases. The design of more efficient thin film cooling geometries/configurations could be facilitated by an ability to accurately model and predict the effectiveness of current designs using computational fluid dynamics (CFD) code predictions. Hence, a benchmark set of flow field property data were obtained for use in assessing current CFD capabilities and for development of better turbulence models. Both Particle Image Velocimetry (PIV) and spontaneous rotational Raman scattering (SRS) spectroscopy were used to acquire high quality, spatially-resolved measurements of the mean velocity, turbulence intensity and also the mean temperature and normalized root mean square (rms) temperatures in a single injector cooling flow arrangement. In addition to flowfield measurements, thermocouple measurements on the plate surface enabled estimates of the film effectiveness. Raman spectra in air were obtained across a matrix of radial and axial locations downstream from a $68.07 \mathrm{~mm}$ square nozzle blowing heated air over a range of temperatures and Mach numbers, across a $30.48 \mathrm{~cm}$ long plate equipped with a single injector cooling hole. In addition, both centerline streamwise 2-component PIV and cross-stream 3-component Stereo PIV data at 15 axial stations were collected in the same flows. The velocity and temperature data were then compared against Wind-US CFD code predictions for the same flow conditions. The results of this and planned follow-on studies will support NASA's development and assessment of turbulence models for heated flows.
\end{abstract}

\section{Keywords}

Rotational Raman Spectroscopy, Turbulent Jets, Temperature Measurement, Turbulence Modeling, Tunable Long Pulse Laser, Rms temperature Variations

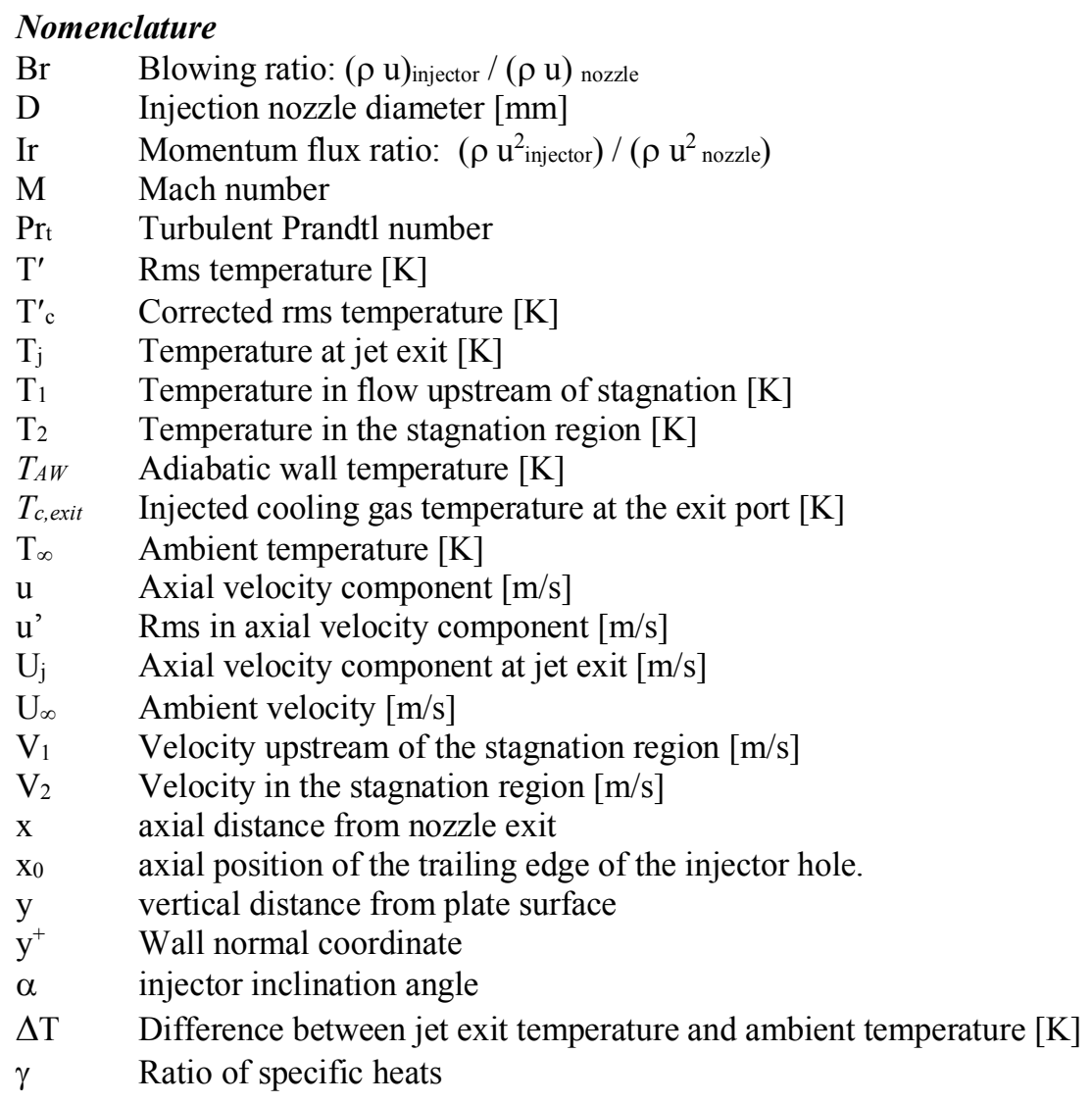


$\rho \quad$ Gas density $\left[\mathrm{gm} / \mathrm{cm}^{3}\right]$

$\sigma_{R E} \quad$ Systematic error in the Raman temperature estimate $[\mathrm{K}]$

$\sigma_{T} \quad$ Measured variation in flow temperature $[\mathrm{K}]$

$\sigma_{T I} \quad$ Normalized rms variation in the temperature of the flow [K]

$\sigma_{M E} \quad$ Measurement error in the estimated temperature from a single shot Raman spectra [K]

$\omega_{\mathrm{x}} \quad \mathrm{X}$-component of vorticity

$\omega_{z} \quad$ Z-component of vorticity

\author{
Abbreviations \\ AAPL AeroAcoustic Propulsion Lab \\ BOS Background Oriented Schlieren \\ CFD Computational Fluid Dynamics \\ GRC Glenn Research Center \\ NPR Ratio of the stagnation pressure of the jet to the ambient pressure \\ PIV Particle Image Velocimetry \\ rms Root Mean Square \\ SHJAR Small Hot Jet Acoustic Rig \\ SRS Spontaneous Raman Scattering \\ TR Ratio of the stagnation temperature of the jet to the ambient temperature
}

\title{
Introduction
}

The performance of advanced gas turbine engines is limited by the cycle temperatures within the engine. Cooling the internal engine surfaces is necessary to maintain the metal surface temperatures within their material property limits. Thin film cooling is predominantly used in gas turbine engines for cooling turbine blades, combustion chamber walls and the liners in afterburning engines [Bogard \& Thole 2005]. Hence, a better understanding of the aerothermodynamics and an ability to accurately predict the performance of thin films using computational analysis tools is required in order to improve engine durability, lifetime and performance. Smith and Mungal (1998) characterized cooling plume trajectories using acetone Planar Laser Induced Fluorescence (PLIF) and determined that the desired feature of film cooling jets is that they are re-entrained into the boundary layer far downstream. The mean properties of the boundary layer recover to their initial state, as if the jet never existed. This distinguishes them from jets for other industrial applications with much higher blowing ratios. Low blowing ratios are desirable in order to avoid generation of a counter rotating vortex pair, which has a sense of rotation that can promote jet lift-off and cause entrainment of heated main flow towards the wall, which decreases the desired film cooling. Thus, a primary consideration in improving film cooling performance is to avoid jet lift off and minimize the entrainment of high temperature main stream fluid near the wall. The design variables having the most impact on the film cooling performance are the inclination angle of the cooling jets, the blowing ratio (Br) and the spatial separation of the jets. It is generally accepted that inclined jets exhibit less penetration and less spreading in the vertical and lateral directions. This indicates that shallower angles provide less lateral mixing than steeper injection holes. Bergeles et al. (1977) performed pitot probe measurements of the flow field formed by a jet inclined $\alpha=$ $30^{\circ}$ to a flat plate. The maximum effectiveness and coverage occurred at a blowing ratio $\mathrm{Br} \approx 0.5$, after which the jet began to lift off the wall. Baldauf et al., (2001) used IR cameras to estimate adiabatic film cooling effectiveness over a range of inclination angles, hole pitch and blowing ratios, where again the $30^{\circ}$ inclination angle and $\mathrm{Br} \approx 0.5$ were determined to be optimal.

In many of these past works on thin film cooling, the test hardware is limited to lab scale flows (velocity $<20 \mathrm{~m} / \mathrm{s}$ ) and small temperature differences or high density simulant gases are used so that the instrumentation can survive the environment [Mee 1999, Bergels et al., 1977, Andreopoulos 1984]. Nearly all of these investigations used measurements of the material surface properties to estimate the film cooling effectiveness or the thermal heat transfer coefficient, which are prone to several error sources if not properly calibrated. These lab scale flows also fail to capture all of the relevant physics that are present at the more realistic high temperature and transonic conditions of actual jet engines. One of the few realistic engine condition tests was performed on cooling turbine blades in a blowdown test rig utilizing heat flux gauges to measure heat transfer and surface temperatures but not the gas temperatures [Haldeman, 2006]. Another turbine blade cooling experimental test at transonic speeds using simulant high density gas was performed using liquid crystals to measure surface heat transfer [Poinsatte, 2008]. Besides pitot probe measurements [Bergeles et al. (1977)], the only other off body measurements in thin film cooling flows have been made using hotwire anemometry, performed in low speed flows so that the probes will survive [Andreopoulos 1984, Shyam, et al. 2014].

Computational fluid dynamics (CFD) predictions at transonic speeds and high temperatures are handicapped by a lack of experimental data available to validate results. The typical practice [Yoder, 2016a] utilizing a Reynolds-averaged Navier- 
Stokes approach, is to use a linear two-equation turbulence model, and then employ a constant turbulent Prandtl number, $\mathrm{Pr}_{\mathrm{t}}$, to represent the turbulent heat flux terms in the energy equation. While surface heat transfer coefficients are important, the more complex momentum and heat transfer occurring in the shear layer between the large temperature and velocity gradients are even more important to accurately model. Hence, the objective of this work is to acquire a comprehensive, high quality set of temperature data and Particle Image Velocimetry (PIV) measurements in a relevant environment. Traditional measurement techniques (pressure transducers and hotwire anemometry), and specifically those for temperature (thermocouples and hotwires), typically cannot survive in the hostile high temperature, high velocity flows of relevance. They are either severely restricted in temporal response, suffer from limited spatial resolution, or have a limited lifespan once in contact with the flows. Their accuracy is also questionable since they are intrusive to the flow and as such disturb and alter the very phenomenon that they are attempting to measure. Non-intrusive measurement techniques are the preferred approach for measuring the flow field properties.

PIV is the defacto standard for measuring flow velocities and is readily applied in the high temperature, transonic flow as required in this work [Bridges \& Wernet, 2003]. While PIV systems are ubiquitous and commercially available, there are no such options for acquiring non-intrusive temperature measurements. Rayleigh spectroscopy has been utilized in jet flow facilities to measure the flow parameters such as velocity, density and temperature [Panda, et al. 2005, Mielke \& Elam, 2009] however, while the velocity and density data were of good quality, the rms temperature data are of lower quality and were frequently contaminated by entrainment of particulates in the flow. The Rayleigh technique also requires a complex optical system setup and is very sensitive to ambient light, flare light and vibration. Coherent Anti-Stokes Raman Spectroscopy (CARS) is a complex optical technique requiring precise alignment of three coincident laser beams and has been used to obtain average temperature in high speed and reacting flows. The CARS technique is also plagued by a very complex optical setup and the associated alignment issues thereby requiring the laser to be remotely located in a climate controlled room [Cutler et al., 2014, Tedder et al., 2009]. Transient Grating Spectroscopy (TGS) has also seen recent application to temperature measurement. While this technique has seen a recent success in temperature measurement within jet flows [Kuehner, 2010], it too suffers from a complex optical setup requiring precise alignment of multiple laser beams and as such is not amenable to large scale, outdoor facilities. Vibrational and rotational Raman spectroscopy are inelastic scattering techniques that have been used quite successfully to perform temperature measurements on a variety of flows. Single-shot vibrational Raman thermometry has been performed in flames [Ajrouche, 2014] where a fast optical shutter was used to minimize flame emission which would otherwise obscure or interfere with the SRS spectrum. Vibrational Raman is ineffective in low temperature regimes due to the lack of the antiStokes bands; however, pure rotational Raman spectroscopy, which is not dependent upon anti-Stoke lines, has been used to interrogate expanding supersonic flows of $\mathrm{CO}_{2}$ for measuring temperature [Maté, et al., 1998]. Rotationally resolved Raman has more recently been used to acquire mean and rms temperature measurements in high temperature flows, from subsonic to supersonic speeds in harsh real world test facilities [Locke \&Wernet, 2017]. Rotationally resolved Raman scattering is the only technique which is simple to setup/align and robust against the hostile environments found in real world aerospace simulation facilities; therefore it is the technique of choice for measuring the gas temperatures in thin film cooling - shear layer flows of interest in this work.

\section{Project Description}

NASA's Turbulent Heat Flux (THX) task under the Transformational Tools \& Technologies project is focused on acquiring benchmark temperature and velocity data in turbulent shear layers for validation of computational fluid dynamics (CFD) codes. Standard CFD turbulence models lack the ability to accurately calculate a number of fundamental flow phenomena, including the turbulent transport of heat. In nearly all production class Reynolds-averaged NavierStokes (RANS) CFD codes, a gradient-diffusion approximation is used whereby a constant turbulent Prantdl number, Prt, is used to relate an eddy viscosity calculated for the momentum terms, to the turbulent heat flux terms. The default in most CFD codes is $\operatorname{Pr}_{t}=0.9$, however this is not representative of all flows. As discussed in Yoder et al. [2015] and Reynolds [1974], $\mathrm{Pr}_{t}=0.7$ is felt to be more appropriate for jets. Recent work, as discussed in Yoder [2016a], has explored more complex formulations including variable turbulent Prantdl number models. A key difficulty in developing more accurate models for the turbulent heat flux is the lack of experimental data that quantify the turbulent thermal state. There have been minimal measurements made for turbulent heat flux problems outside of simple wall bounded flows [Kays 1994]. Therefore, the focus of the Turbulent Heat Flux task has been to acquire a dataset of $1^{\text {st }}$ and $2^{\text {nd }}$ order velocity statistics along with mean temperature and root-mean-square (rms) temperatures with high accuracy and high spatial resolution. The THX Step I experiments were conducted in a small scale wind tunnel where Dual-Plane PIV data were acquired using both three and one heated injection air plume(s) into a low speed flow [Wernet, et al., 2016]. The THX Step II tests consisted of acquiring Raman temperature measurements, using the same laser/optical hardware applied in the work reported here, in the flow of a $50.8 \mathrm{~mm}$ diameter heated jet operated over a range of temperatures and Mach numbers [Locke \& Wernet, 2017]. The Raman temperature data were compared with an existing database of PIV data in similar flows enabling assessment of LES predictions of flow velocity, turbulence, mean temperature and rms temperature [Debonis, 2017]. The work reported here represents Step III of the THX task where velocity field and temperature data were acquired for a new configuration having the general characteristics of heated nozzle jet flows 
exhausting over an aircraft afterbody and requiring active cooling. However, the geometry was simple enough in geometric arrangement to allow for detailed velocity and temperature measurements (mean flow and turbulence) to characterize the fluid dynamics and thermodynamics - especially for computational model validation, assessment, and hopefully eventual development.

The test article in this work consisted of a square nozzle blowing hot flow over a flat plate/deck. A single air injection hole in the plate delivered cooling flow into the primary nozzle's hot jet flow over the plate. Note that in a realistic aircraft component application, whether it is an aircraft engine turbine blade, internal nozzle surface, or afterbody, typically a very large number of small holes are used to provide the cooling film near the surface. In the experiments conducted here, a single large cooling hole is used to cool a large flat plate with a heated flow blowing over the plate. The motivation was to obtain detailed aerothermal data in the vicinity of the interaction region of the single injected cooling air stream with the primary flow stream that is heated. The following flow measurements were acquired: (1) PIV for velocity statistics, (2) rotational Raman scattering for temperature data, and (3) thermocouple surface temperature measurements on the plate extension. The objective of the tests described herein are to collect $1^{\text {st }}$ and $2^{\text {nd }}$ order velocity statistics along with mean and normalized rms temperature measurements via PIV and rotationally resolved Raman spectroscopy across a precisely defined measurement grid in the plume of a convergent hot jet. The acquired data should be useful for validation of CFD turbulence models since regions of high turbulence are assumed to be the regions of peak fluctuations in temperature.

The AeroAcoustic Propulsion Laboratory (AAPL) at NASA GRC was selected for this series of tests since it can provide the heated and injection air flow streams necessary for simulating thin film cooling. The AAPL has a number of features that make implementing optical diagnostics a challenge: 1) The AAPL is open to the outside environment and as such experiences large temperature variations over the course of a day-long test, 2) High sonic noise levels upwards of 115 $\mathrm{dB}, 3$ ) High ambient light levels due to the large, $55^{\prime}$ wide by $36^{\prime}$ high exhaust-door which must remain open during tests, and 4) Inaccessibility by personnel during the tests. Taking all of the above into consideration Rotational Raman was selected as the temperature diagnostic for this test due to the relative simplicity of its installation and robustness against hostile environments (temperature variations and high vibration levels) compared to the complex and sensitive alignment requirements for the other optical techniques described above. PIV was likewise chosen as the flow measurement diagnostic due to our longstanding experience in applying PIV in the SHJAR facility at GRC [Bridges and Wernet, 2011].

\section{AAPL Laboratory, SHJAR and Experimental Setup}

All the data presented herein was obtained on the Small Hot Jet Acoustic Rig (SHJAR) located within the AeroAcoustic Propulsion Laboratory (AAPL) at NASA GRC. The SHJAR (Figure 1) is a single flow stream free jet rig capable of operating over a range of Mach numbers up to $\mathrm{M}=2$ at static temperature ratios up to 2.8. The AAPL (Figure 2) is a 19.8 $\mathrm{m}$ radius geodesic dome with its interior walls covered by sound absorbing wedges providing a near anechoic environment. The centerline of the nozzle exit of the SHJAR is $3 \mathrm{~m}$ above the floor. Vitiated flow heating up to $830 \mathrm{~K}$ is provided by an inline hydrogen combustor and supply air is provided by central compressor facilities, permitting continuous operation. The fuel-air mass flow ratios for heating the supply air ranged from $2.8 \times 10^{-4}$ to $7.2 \times 10^{-3}$ resulting in a negligible change in the nitrogen to oxygen ratio of the heated air at the nozzle exit and over the flat plate.

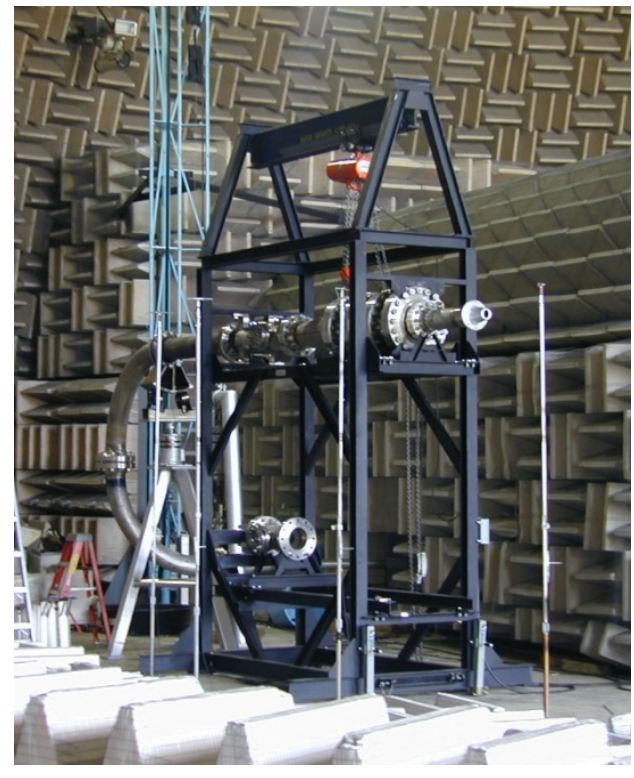

Figure 1. Photograph of the SHJAR facility.

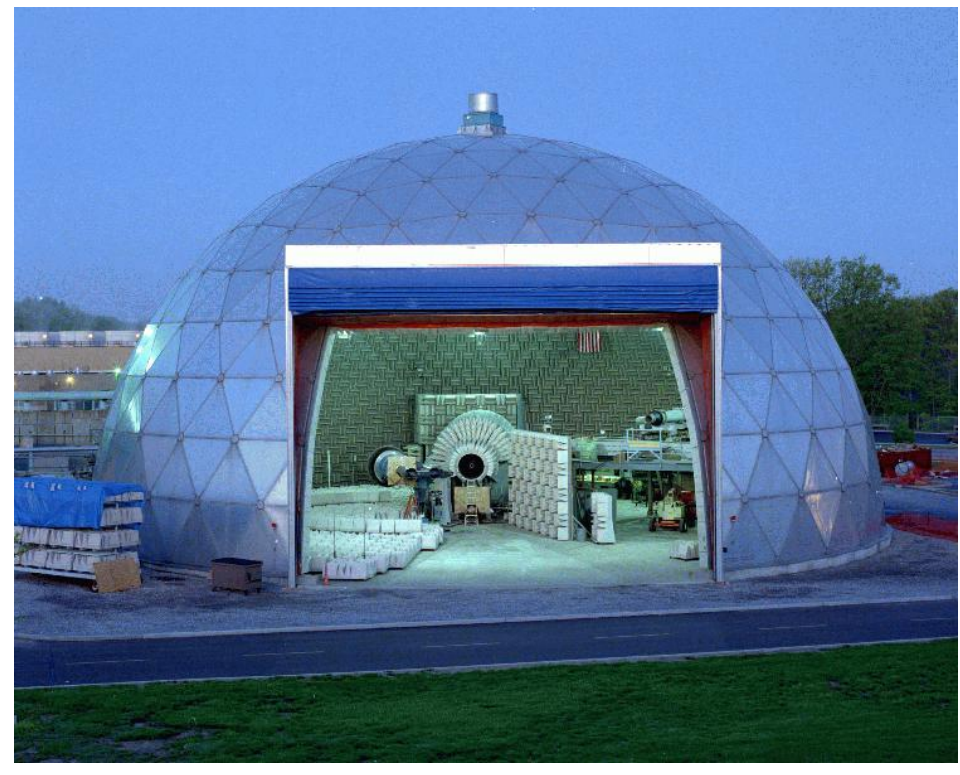

Figure 2. Photograph of the AAPL laboratory. SHJAR is the smaller rig left of center. 
The SHJAR facility is frequently used for PIV measurement studies where aluminum oxide is used to seed the flow. Raman scattering is a molecular scattering technique and as such any particulates in the flow are detrimental to the quality of the acquired Raman signals, hence, simultaneous velocity and temperature measurements were not feasible. As an additional preparation for the test, the SHJAR was disassembled and cleaned of any residual seed material coating the inside flow passages of the rig/model hardware. As an extra precaution the supply air was filtered to eliminate any residual particulate matter entrained in the flow. The Raman portion of the test program was conducted first, followed by the PIV measurement campaign, with the requisite particulate seeded flow streams.

For this THX Step III test, a new nozzle was designed that transitions from a $152.4 \mathrm{~mm}$ radius round cross section through a series of super ellipses to a square nozzle with $68.07 \mathrm{~mm}$ sides at the nozzle exit. This square nozzle exit shape was chosen in order to provide a volume of uniform flow over the plate surface where the hot exhaust interacted with the injection stream. The dimension of $68.07 \mathrm{~mm}$ was determined to be the largest that would correspond to a nozzle mass flow that would not overly strain the SHJAR. See Figs. 3 and 4 for conceptual drawings of the test hardware. The nozzle internal contour was designed to have a continually decreasing cross sectional area while moving downstream, to enable a favorable pressure gradient, and in turn, minimal secondary flows at the nozzle exit. A flat plate or deck was mounted to the square nozzle to form the nozzle/deck assembly. The plate spans the width of the nozzle exit and extends 304.8 $\mathrm{mm}$ axially from the nozzle exit. In Fig. 3, a $68.07 \mathrm{~mm}$ wide by $25.4 \mathrm{~mm}$ thick plate is shown with a $15^{\circ}$ tapered end. A total of 18 thermocouples were embedded along the length of the plate extending from the nozzle exit. Holes were drilled from the underside of the plate leaving just $0.762 \mathrm{~mm}$ of material between the epoxy potted thermocouple and the top surface of the plate. Five rows of 3 thermocouples were installed at the following locations: $X=63.5,114.3,165.1$, 215.9 , and $266.7 \mathrm{~mm}$, where $X=0 \mathrm{~mm}$ is at the nozzle exit. At each of the 5 axial locations, three thermocouples were located at span locations of $-25.4,0.0$, and $+25.4 \mathrm{~mm}$, with $Z=0$ being the spanwise plane of symmetry, passing through the center of the injector hole, see Figure 3. Two thermocouples were also embedded at $X=15.9 \mathrm{~mm}$ at $Z= \pm 25.4 \mathrm{~mm}$. The last thermocouple was embedded in the nozzle, at $X=-6.4 \mathrm{~mm}$ and $Z=0 \mathrm{~mm}$. In addition to the embedded thermocouples, 5 surface mounted thermocouples were spot welded to the bottom surface of the plate, at axial stations of 88.9, 139.7 and $190.5 \mathrm{~mm}$ from the nozzle exit. A thermocouple was inserted into the cooling air flow tube approximately $381 \mathrm{~mm}$ from the top of the plate. The air temperature inside of the seed mixing plenum was also equipped with a thermocouple.

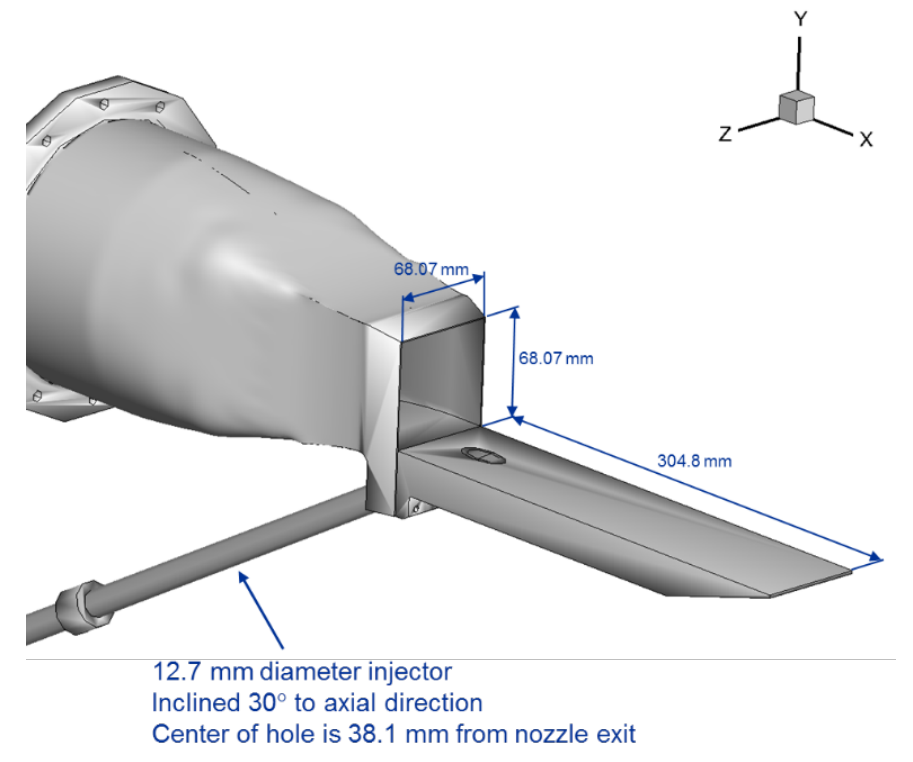

Figure 3: Experimental configuration - square nozzle with the $25.4 \mathrm{~mm}$ thick plate and $12.7 \mathrm{~mm}$ diameter injector hole. 


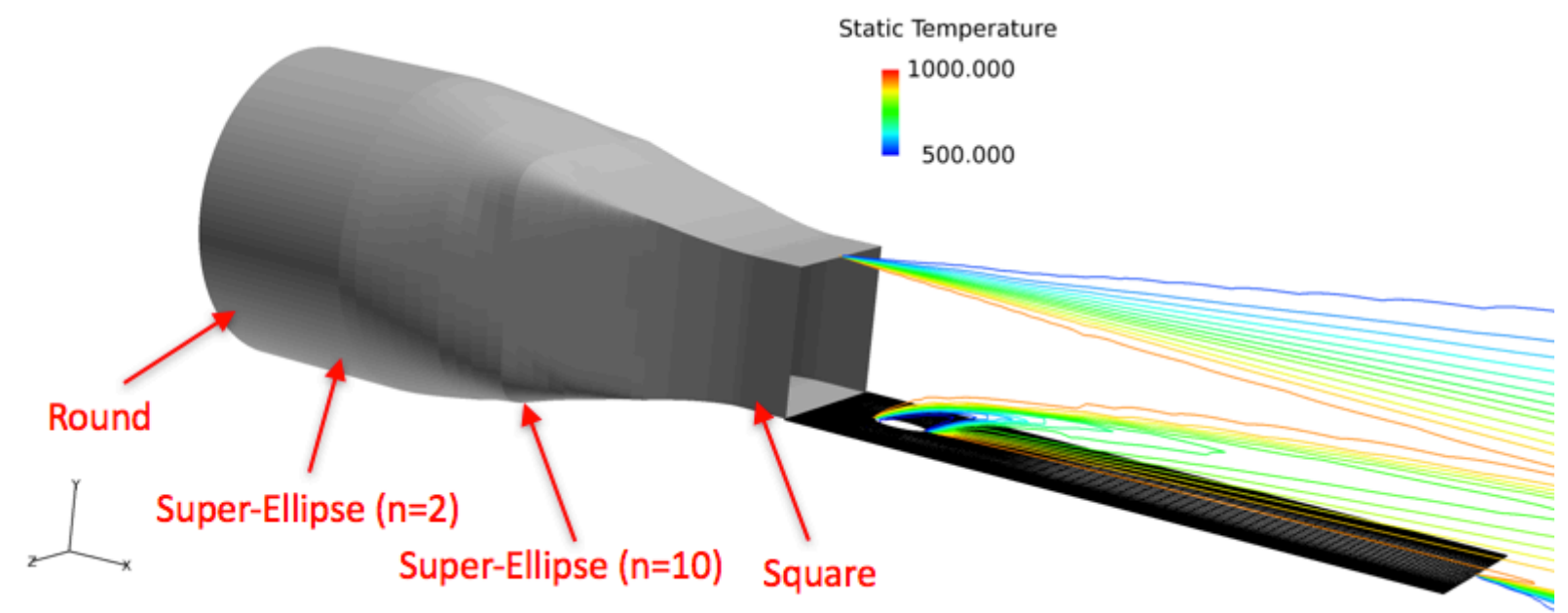

Figure 4: Side View of preliminary CFD showing temperature contours along $z=0$ plane of symmetry.

As shown in Fig. 3, a single cooling flow tube (also termed injector) delivers flow through a $12.7 \mathrm{~mm}$ diameter cross section and exits flush with the top of the plate surface. The center of this flow passage intersects the plate surface at 38.1 $\mathrm{mm}$ downstream of the nozzle exit. The tube is inclined at 30 degrees from the axial direction and is $508 \mathrm{~mm}$ long (length / diameter $=40$ ) to enable a fully developed boundary layer by the flow exit at the plane of the plate. Because of the 30 degree inclination, the round tube cross section forms an ellipse at the surface of the plate extends with a minor axis of $12.7 \mathrm{~mm}$ and a major axis of $25.4 \mathrm{~mm}$ in the axial (x) direction, with leading edge at $\mathrm{x}=25.4 \mathrm{~mm}$ and trailing edge at $\mathrm{x}$ $=50.8 \mathrm{~mm}$.

Figure 4 shows temperature contours along the spanwise symmetry plane (cutting test configuration at $Z=0$ plane) for a preliminary RANS CFD case used to qualitatively characterize the flow for test model design. In the CFD that was conducted prior to the hardware fabrication and experiments, several variations in plate geometry, especially plate width, were examined. These variations resulted in no noticeable effect on the shear layer development above the plate. For structural integrity, a 1.0 inch thick plate was selected for the final design.

The cooling flow tube originates at a plenum box, where unheated shop air (at nominally the ambient air temperature) mixes with PIV seed particles before entering the $40 \mathrm{~L} / \mathrm{D}$ tube. Based on both 1-D and CFD analyses, the pressure drop through the tube was computed to be less than 1 psi from the plenum box to the plate surface. In addition, the flow becomes fully developed in the velocity profile by approximately $30-35 \mathrm{~L} / \mathrm{D}$, based on similar Reynolds numbers to those expected in these tests. However, considering the pressure drop with axial position, and because the flow in the tube will be at sufficiently high Mach numbers (greater than 0.2 but less than 1.0), the velocity profile will never become fully developed, even for L/D much longer than that considered here. Instead, the flow direction momentum ( $\rho u)$ is the quantity that will become fully developed.

\section{Raman Scattering}

Rotationally resolved Raman scattering has been previously used to measure gas temperature in heated high speed jet flows in the SHJAR facility at NASA GRC [Locke et al., 2017]. A thorough discussion of Raman spectroscopy theory and practices can be found in Ferraro and Nakamoto [18]. In general, Raman is an inelastic scattering process, with a signal intensity approximately $10^{-3}$ of that from Rayleigh scattered light. Raman scattering is not dependent on wavelength but is linear with respect to the species number density and is species specific by virtue of the quantization of individual molecular energy states. Here we are not concerned with determining the composition of the gas being probed (heated air), just the gas temperature, which greatly simplifies the data analysis and reduction.

\section{Raman Measurement System}

The key features in the layout of the Raman temperature diagnostic are shown in Figure 5. A 10Hz Continuum long pulse length Agilite Nd:YAG laser with $600 \mathrm{~mJ}$ of energy at $532 \mathrm{~nm}$ spread across $200 \mathrm{nsec}$ was used to probe the flow temperature and still avoid breakdown of the gas. The $9 \mathrm{~mm}$ diameter output beam was focused by a $500 \mathrm{~mm}$ spherical lens to a roughly $70 \mu \mathrm{m}$ beam waist. The rotational Raman scattered signal was collected by two matched f/1.4, $85 \mathrm{~mm}$ Nikon lenses set at a 4.0 f-stop. A pair of lenses was used in order to maximize the collected signal. The lenses were vertically mounted and focused on the laser focal volume approximately $530 \mathrm{~mm}$ distant. Each lens was displaced from 
the horizontal plane and tilted by $6^{\circ}$ (upper $-6^{\circ}$, lower $+6^{\circ}$ ), which is nominally the closest point the lenses could be mounted together.

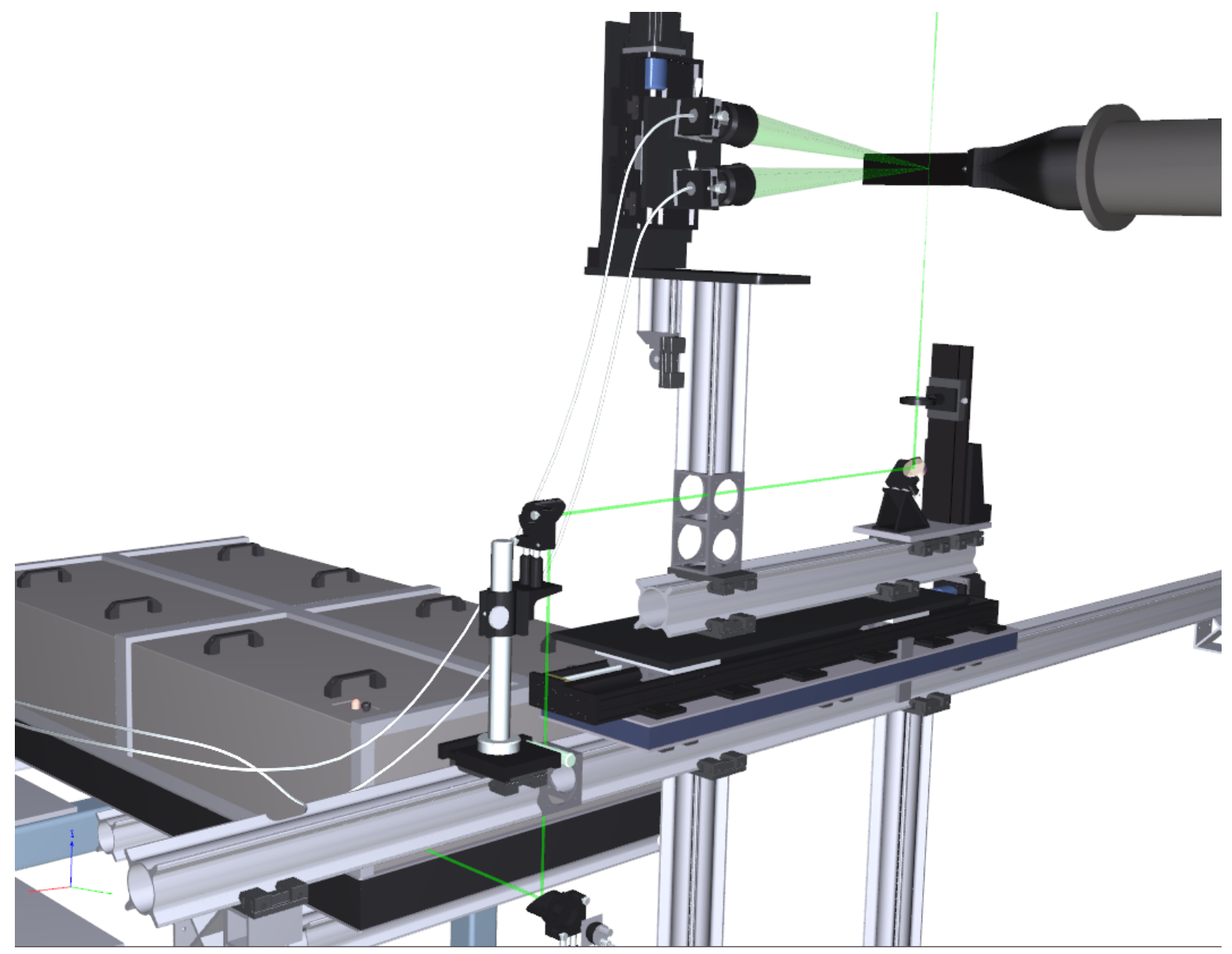

Figure 5. Schematic of the rotational Raman collection optics as installed in the SHJAR facility.

The light captured by each lens was passed through a $532 \mathrm{~nm}$ RazorEdge long-pass $24.5 \mathrm{~mm}$ filter attached to the rear of each camera lens mount. The filtered light was focused onto a bifurcated fiber bundle from Fiberoptic Systems, Inc.. The input ends of the bifurcated fiber bundle each contained $57100 \mu \mathrm{m}$ diameter fibers which were formed into a linear array at the output end of the bundle. The linear fiber bundle output was coupled to the entrance slit of an Acton $500 \mathrm{~mm}$ imaging spectrometer with an 1800 gr ruled grating and a wavelength centerline of $537 \mathrm{~nm}$ resulting in a spectral wavelength span of approximately $12 \mathrm{~nm}$. Since the $100 \mu \mathrm{m}$ fibers of the transmission bundle were arranged linearly at the slit, the slit of the spectrometer was opened to its maximum of $2.0 \mathrm{~mm}$ allowing the fibers to act as their own $100 \mu \mathrm{m}$ slit. A PI-MAX2 ICCD camera with $18 \mathrm{~mm}$ diameter gated intensifier from Princeton Instruments was coupled to the exit of the spectrometer and the resultant rotational Raman spectra captured using Princeton's WinSpec32 software. To verify alignment of the $532 \mathrm{~nm}$ laser pulse, the thermocouple and the two camera lenses, a $635 \mathrm{~nm}$ diode laser was fiber-coupled to the rear of the two $85 \mathrm{~mm}$ collection lenses and directed back to the probe volume, where the alignment of all three components of the measurement system could be visually confirmed by the intersection of the back projected/focused diode laser beams. The Raman measurement volume is defined by the intersection of the laser beam diameter and the two $85 \mathrm{~mm}$ lens collection cones. The length of the $70 \mu \mathrm{m}$ diameter collected by the $85 \mathrm{~mm}$ lenses is defined by the size of the fiber bundle used to collect and transmit the light to the spectrometer. The entrance face of the fiber bundles are $1.1 \mathrm{~mm}$ in diameter. The $85 \mathrm{~mm}$ lenses image a $6 \mathrm{~mm}$ length of the laser beam onto the face of the fiber bundle. The resulting cylindrical probe volume used in this work is $4.3 \times 10^{-3} \mathrm{~mm}^{3}$.

\section{Raman Data Processing}

To extract temperature from the rotational Raman spectra, an iterative process was developed which determines the best fit between the measured spectrum and the spectrum computed using a pure-rotational Raman scattering model, which is 
described in more detail in Locke et al., 2017. To model the Raman scattering spectrum an assumption is first made that the gas composition is a mixture of only molecular nitrogen and oxygen. This can be done since the measurements are made in air and other atmospheric gaseous components do not contribute significantly to the Raman signal. For a given temperature, the model computes Raman line locations and strengths in the Raman Stokes (S) bands of nitrogen and oxygen up to rotational quantum numbers of 50. The merged array of Raman lines for $\mathrm{N}_{2}$ and $\mathrm{O}_{2}$ with their respective strengths and wavenumbers, is then convolved with a Voigt kernel derived from the spectral profile of the pump laser wavelength peak as measured through the optical system.

In the data processing stage, the 1000 single-shot spectra were read into a Matlab-based data reduction software. In each acquisition sequence, there were typically several bad spectra due to the wait time of the camera/spectrometer/image intensifier. Additionally, there were times when particulates in the flow passed through the measurement volume producing strong signals at the laser line wavelength, which were strong enough to yield Rayleigh/laser line peaks of higher intensity than the Raman signal. In order to remove these spurious spectra, the data set was sorted to remove the 10 highest amplitude spectra, hence only 990 single shot spectra were used in each ensemble.

The 990 spectra were then used to compute an average spectrum, which was fit to the $\mathrm{O}_{2} / \mathrm{N}_{2}$ model function using a combined genetic algorithm for the global search followed by a local search using a non-linear least squares (NLLS) routine. The model parameters used in the fit included the temperature, the Raman signal amplitude, the kernel width (a 2-parameter Voigt instrument function) and the spectrometer grating calibration parameters, which included the laser line center location. The fit of the mean spectra provided the initial estimates for all of the single shot spectral fits. The estimated temperatures from the processed spectra were then used to compute the mean temperature estimate and the rms temperature across the ensemble, $\mathrm{T}^{\prime}$. The time to process the 990 spectra was on the order of 1 minute on a 20 core based CPU. A sample averaged spectrum acquired at $547 \mathrm{~K}$ and its corresponding fit are shown in Figure 6.

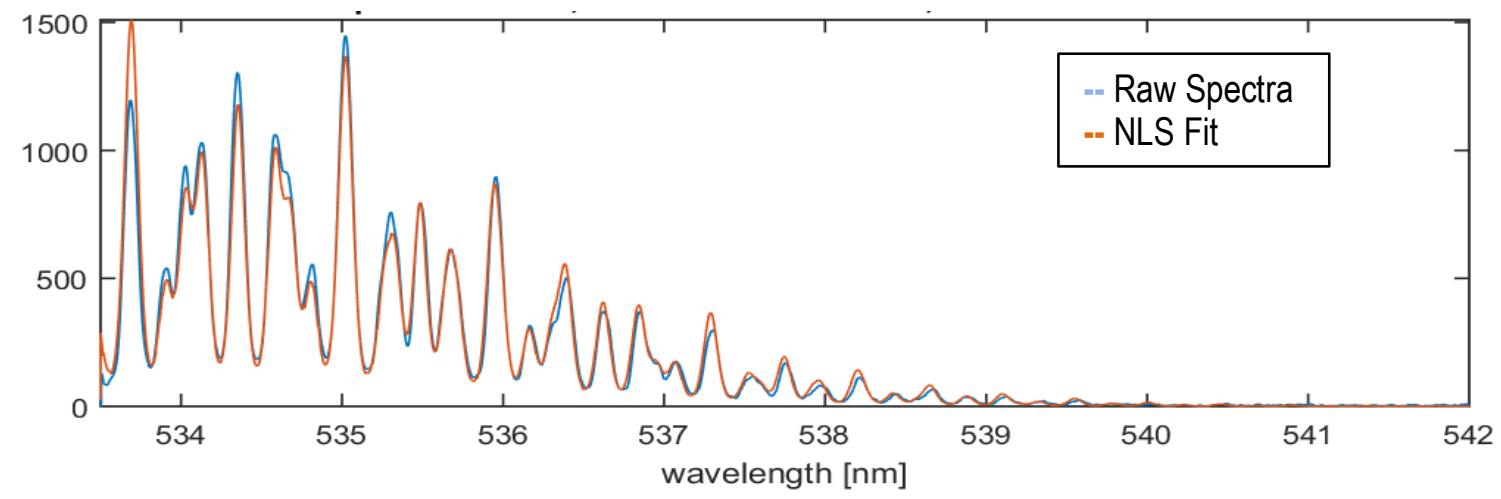

Figure 6. Sample averaged rotational Raman temperature spectrum with fit for $\mathrm{T}_{\text {cal }}=547 \mathrm{~K}$. The spectrum is elongated in the $\mathrm{x}$-axis to show detail.

\section{Raman System Calibration}

The Raman technique samples the molecules in the probe volume in order to estimate the gas temperature. The molecules in the probe volume can have any one of a number of states as defined by the Boltzmann distribution. The number of populated states increases with temperature, hence the rms temperature increases with increasing temperature of the gas. This is a known and documented characteristic of the technique, which is actually a systematic measurement error [Locke et al., 2017]. A calibration of the Raman system in a well characterized environment free from flow turbulence of other noise sources is required in order to characterize this inherent rms temperature variation in the technique. A lab scale setup using the concentrated output from an electrical heat gun calibrated using a thermocouple was used to acquire the calibration data [Locke et al., 2017]. The Raman spectra acquired at the 13 different temperature settings on the heat gun were processed according to the procedures described in the preceding data reduction discussion. The ensemble of 990 measurements at each point are used to compute the mean and rms gas temperature. Figure 7 plots the mean temperature of all 990 accumulated spectra along with the rms error bars at each temperature. The mean calibration temperature measurements are found to be accurate to $<2.5 \%$ over the range of $296 \mathrm{~K}-850 \mathrm{~K}$. Here accuracy is defined as the deviation of the measurement from the true (known) value. For these calibration measurements the mean temperature level is measured using a thermocouple. The reported error is the deviation of the Raman based mean temperature measurement from the thermocouple measurements. 


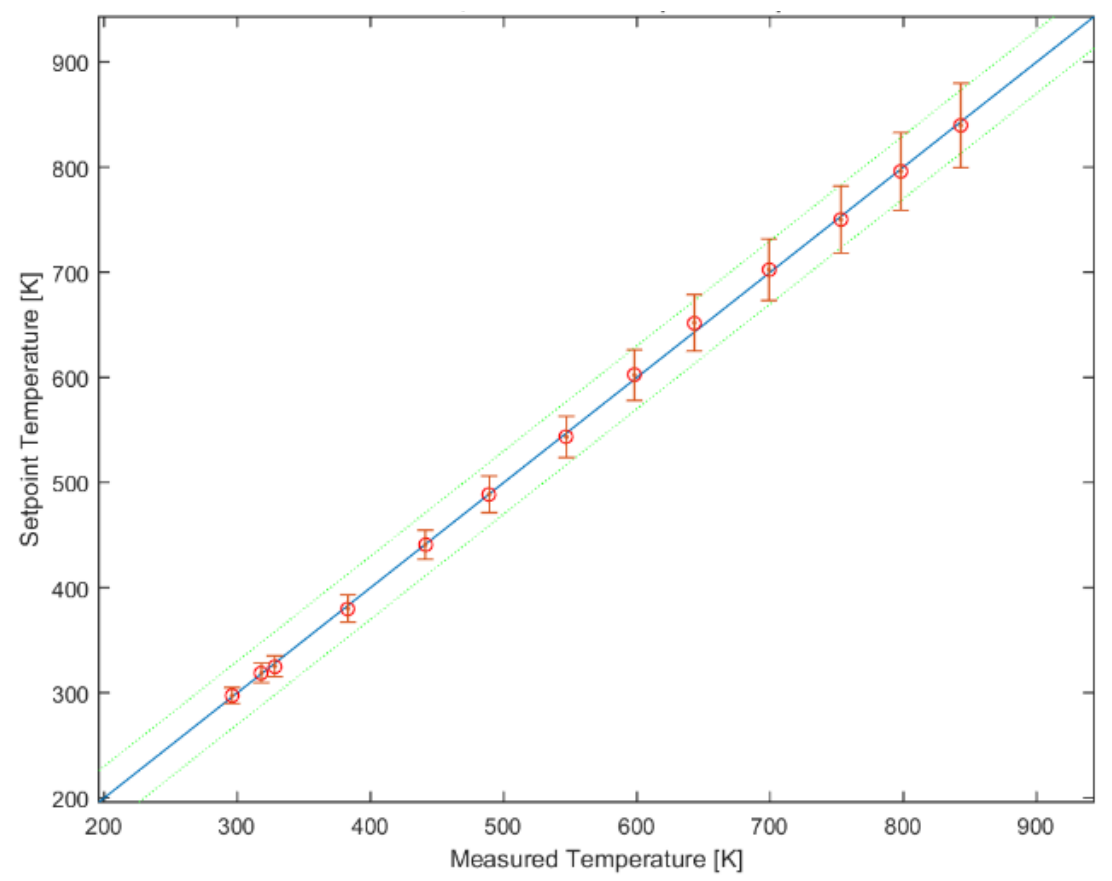

Figure 7. Plot comparing the thermocouple reading versus the calculated Temperature and the RMS variations (plotted as error bars) in temperature over the range of calibration temperature range settings.

The Raman based calibration rms temperature estimate is $\pm 2.2 \%$ at $296 \mathrm{~K}$ and $\pm 4.5 \%$ at $850 \mathrm{~K}$. The Raman temperature measurements reported here illustrate the best case measurement accuracy that can be expected using the Raman Thermometry diagnostic. The Raman measurements contain 3 main contributions to the rms variations: 1) random measurement error $\left.\sigma_{M E}, 2\right)$ flow turbulence $\sigma_{T I}$, and a systematic error in the Raman diagnostic $\sigma_{R E}$, as shown in equation 1. These error sources add in quadrature to yield the total rms variation in the measured temperature. The large ensemble of 990 is used to drive down the random measurement error by $1 / \sqrt{ } \mathrm{N}$. Larger samples sizes were collected, but yielded no further reduction in the observed rms variations. Dynamic thermocouple measurements in the heat gun flow showed that the $\sigma_{T I}$ is negligible for the calibration measurements [Locke at al., 2017]. Hence, the remaining contribution to the observed rms variation is the inherent systematic error in the Raman technique.

$$
\sigma_{T}^{2}=\sigma_{M E}^{2}+\sigma_{T I}^{2}+\sigma_{R E}^{2}
$$

The calibration plot error bars in Figure 7 clearly delineate that the measured rms increases linearly with temperature, as stated above. A linear fit to the rms temperature as a function of the known temperature yields a relation for the expected systematic error in the Raman based temperature diagnostic:

$$
\sigma_{R E}=0.057 T-11.92 \mathrm{~K}
$$

This expression will be used later to predict the expected systematic error resulting from the Raman temperature measurement technique when we examine the rms temperature measurements in the heated jet, cooling film flows.

\section{Raman System Installation in SHJAR}

The same optical excitation and detection system used to acquire the Raman temperature laboratory calibration was also used in the performance of actual testing in the AAPL. The long-pulse, Agilite laser, beam insertion optics, detection optics and spectrometer/camera detection systems were transported, installed, and aligned in the AAPL as shown in Figure 8. Note that the film cooling plate with the single air injection hole was mounted perpendicular to the floor in order to provide convenient optical access for the long pulse laser beam. Due to the size of the laser, the Agilite laser had to be mounted inside the frame of the large traverse system, which necessitated the orientation of the film cooling plate orientation. The beam from the laser was directed towards the front face of Big-Blue where it was turned vertically using a mirror. A catching mirror then turned the laser beam horizontal and parallel to the front face of Big-Blue. A final turning mirror turned the laser beam vertical so that it passed vertically through the jet flow field. A $500 \mathrm{~mm}$ focal length spherical lens then focused the beam at the center of the flow, downstream of the nozzle's exit plane. The final turning mirror, lens and the camera collection lenses are mounted on a long Velmex translation stage which provides the transverse surveys of the jet/plate cooling flow. 


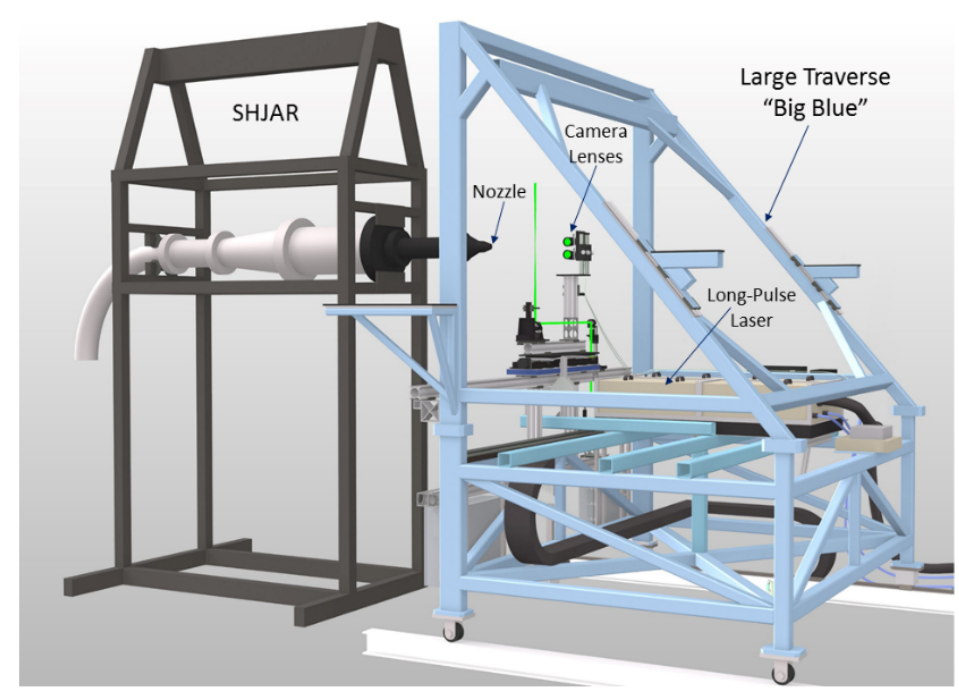

Figure 8. SHJAR and large traverse "Big Blue" loaded with the long-pulse laser and optical diagnostics.

The vertical position of the measurement volume was adjusted using a second Velmex translations stage. The vertical translation stage adjusted the position of the collection lenses along the focused laser beam. The focus of the laser beam was not adjusted for the vertical translations, which spanned a $50.8 \mathrm{~mm}$ region along the beam waist. The data obtained in the AAPL were acquired over a grid of measurement locations for eleven experimental Set Points that covered a wide range of flow conditions. CFD solutions run prior to the actual testing in the SHJAR were used to determine the best locations for the Raman temperature measurements.

\section{PIV Measurement System}

For the PIV portion of the measurement campaign, the plate with the injection hole was mounted parallel to the ground. Data were acquired using two different PIV configurations: one mapping cross-stream planes, with the cameras mounted in a stereo configuration to obtain 3-components of velocity; and another mapping the nozzle/plate centerline plane using a dual side-by-side camera configuration to obtain 2-components of velocity.

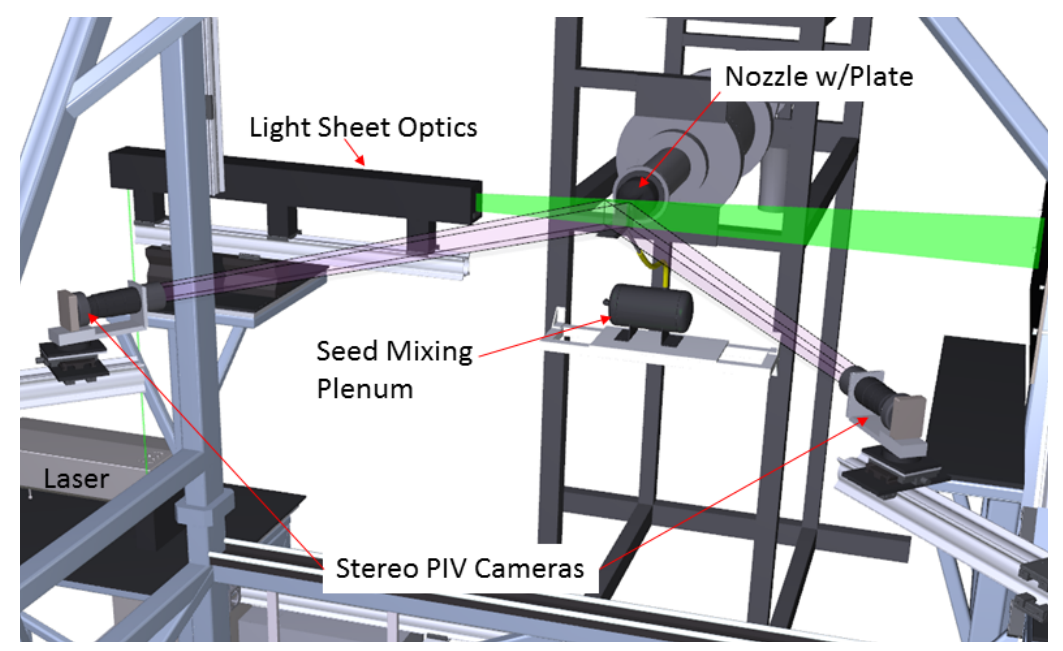

Figure 9: Cross-stream Stereo PIV installations on the large blue traverse system in the SHJAR.

\section{3-C SPIV Configuration}

The Stereo Particle Image Velocimetry (SPIV) system was configured to provide cross-stream measurements of the three-component (3C) velocity field from the test article. The entire SPIV system was mounted on the large 
traverse system to perform velocity plane surveys of the flow field as shown in Figure 9. The travel range of the traverse was approximately $2.133 \mathrm{~m}$, with a positioning accuracy of $1 \mathrm{~mm}$. The SPIV system employed two high-resolution (4008×2672 pixel) cameras equipped with $300 \mathrm{~mm}$ focal length lenses, $1.4 \times$ teleconverters and $8 \mathrm{~mm}$ extension tubes to provide a 100x100 mm field-of-view. The cameras were mounted downstream of the model exit plane at nominally $\pm 45^{\circ}$ from the nozzle centerline. Both cameras were connected to a single computer system via a CameraLink PCI card and the 400 frame pair data sequences were acquired and streamed to disk at a rate of 2 frame pairs/camera/sec. Stereo PIV calibrations were performed using a single plane target translated to 9 axial positions over a $\pm 2 \mathrm{~mm}$ range. A 4th order polynomial was used in the image warping and a calibration verification operation was employed to insure the calibration overlapped the laser light sheet plane.

\section{2-C Streamwise PIV Configuration}

A standard PIV system was used to measure the 2-component (2C) streamwise velocity field down the centerline of the plate. In order to maximize the field of view while maintaining high spatial resolution PIV vector maps, a dual side-by-side camera configuration was used to acquire the centerline streamwise plane of data, as shown in Figure 10. By orienting the 4008x2672 pixel PIV cameras in landscape mode (4008-pixel axis oriented horizontally) the entire length of the plate could be imaged without traversing the PIV system, shown as the centerline plane in Figure 11. The cameras were equipped with $135 \mathrm{~mm}$ focal length lenses with $8 \mathrm{~mm}$ extension tubes and positioned so that their fields of view overlapped by $25.4 \mathrm{~mm}$. A flat, SPIV-style calibration target was used to calibrate and register the two cameras using a fiducial mark in the overlapping region of the cameras' field of view. The physical registration of the two cameras was used in the setup of the vector processing grids in the left and right camera images so that no interpolation was required in the merging of the left/right vector maps. The final merged camera vector map covered an area of 125x317.5 mm.
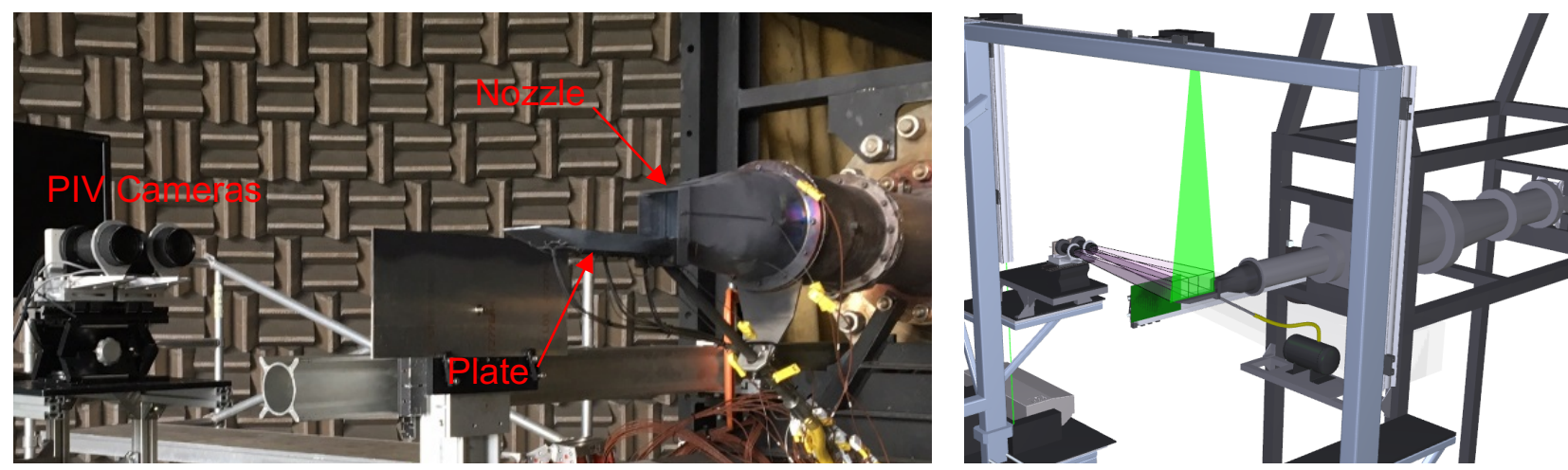

Figure 10: a) Streamwise 2-component PIV installation on the SHJAR showing dual side-by-side cameras and seeder mixing tank; b) the CAD rendering shows the laser light sheet impinging down on the centerline of the plate from above.

The PIV measurement plane was illuminated using a dual head $400 \mathrm{~mJ} /$ pulse Nd:YAG laser system. For the SPIV system, the laser beams were formed into $1 \mathrm{~mm}$ by $100 \mathrm{~mm}$ high light sheets using cylindrical and spherical lenses, see Figure 9. The light sheets were directed horizontally across the plate, parallel to the surface of the plate. The axial locations measured were at 12.7, 25.4, 38.1, 50.8, 63.5, 76.2, 88.9, 101.6, 114.3, 127, 139.7, 152.4, $165.1,190.5,215.9$, and $266.7 \mathrm{~mm}$ from the exit plane of the nozzle, as depicted in Figure 11. For the streamwise PIV measurements, the laser light sheet was expanded into a $1 \mathrm{~mm}$ x $330 \mathrm{~mm}$ wide sheet from overhead and was directed down onto the centerline of the plate, see Figure $10 \mathrm{~b}$. 


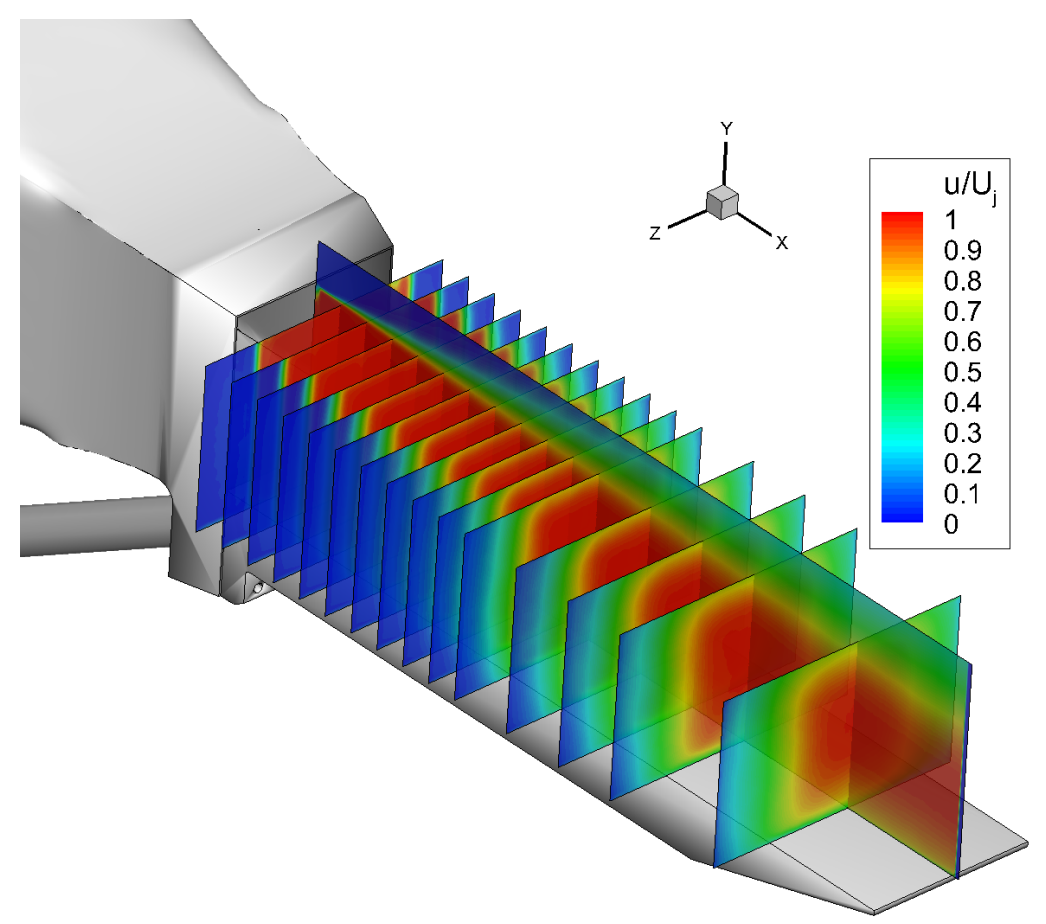

Figure 11: Axial velocity component $\mathrm{u} / \mathrm{U}_{\mathrm{j}}$ in the centerline streamwise PIV plane along with 15 cross-stream planes acquired using stereo PIV.

\section{Vector Processing}

Velocity vector maps for each camera were computed from the image pairs using the in-house PIVPROC software. The software utilizes conventional multi-pass PIV cross-correlation processing algorithms and incorporates error detection based on image correlation signal to noise ratio. First-pass interrogation region sizes of 64 x 64 pixels on 32 pixel centers and final-pass interrogation region sizes of $32 \times 32$ pixels on 16 pixel centers were used to process image pairs from the cameras in both stereo configurations. For the cross-flow measurement planes near the nozzle, Symmetric Phase Only Filtering (SPOF) was employed to reduce the effects of flare light on the nozzle models directly behind the measurement planes [Wernet, 2005]. Without the SPOF processing, images with the nozzle illuminated by flare light behind the plane of interest generally produce regions in and around the potential core flow with invalid vector measurements. The SPOF processing technique was not utilized with the axial-flow measurement planes as the nozzle does not appear in the field of view. For the cross-stream SPIV setup, sequences of 400 velocity vector maps were acquired at each measurement station while in the streamwise PIV setup image sequences of 800 were acquired. For both configurations, the image sequences were ensemble averaged to provide first- and second-order statistics over the entire measurement plane. Chauvenet's criterion was used to eliminate any outliers in the ensemble averaging process [Taylor, 1982]. The final streamwise 2C PIV velocity vector maps had a spatial resolution of $1.5 \mathrm{~mm}$, while the final cross-stream SPIV velocity vector maps had $2 \mathrm{~mm}$ spatial resolution. For the $3 \mathrm{C}$ SPIV data, the left/right vector maps were processed with an additional in-house code to generate the 3-D vector maps. The $2 \mathrm{C}$ streamwise PIV system provides the $\omega_{z}$ component of vorticity and the $3 \mathrm{C}$ SPIV data provides the $\omega_{\mathrm{x}}$ component of vorticity. The processed PIV data for both PIV configurations have a full scale measurement error of $1 \%$.

\section{Flow Seeding}

For any type of PIV measurements, the fluid motion being measured is marked by the use of small particles. These particles must be sufficiently small so they will have minimal or no slip relative to the fluid (so that their motion is the same as the fluid motion). In addition, all of the fluid must be laden with particles at a concentration high enough that sufficient particles (5-10) are found in an interrogation region of the recorded PIV images. In tests using the SHJAR, three fluid streams are being mixed: the core heated square nozzle stream, the injected cooling air and the ambient air. It is also crucial that the seed be fully mixed and dispersed in the flow before the measurement region in order to assure good-quality PIV images. Finally, the seed must not be affected by the high temperatures of the gas; this is especially true of the seed in the $800 \mathrm{~K}$ nozzle flow, for the Set Point 49 case. 
The hot nozzle flow was seeded with a refractory seed material, and the ambient air was seeded using a commercial smoke generator. The refractory seed material used for the heated jet flow was $0.4 \mu \mathrm{m}$ diameter alumina powder. A dispersion of the alumina seed material in $100 \%$ ethanol was prepared using a pH stabilization technique [Wernet and Hadley, 2016]. The alumina/ethanol dispersion was introduced into the flow well upstream of the nozzle using an airassisted atomizing nozzle. The $\mathrm{pH}$ stabilization technique provides highly dispersed, unagglomerated seed particles in the flow. The injected cooling air stream was also seeded using alumina, via a fluidized bed seeder system. The injected air was premixed with the dry seed material in a plenum chamber before entering the $\mathrm{L} / \mathrm{D}=40$ injection tube. The total mass flow of injected air was measured, upstream of the seeder, so that the blowing ratio could be accurately set. The ambient fluid was seeded with $0.3-\mu \mathrm{m}$ mineral oil droplets $\left(\rho=0.84 \mathrm{gm} / \mathrm{cm}^{3}\right)$ produced by a commercial 'smoke' generator. A pair of 1-m diameter room circulation fans was used to disperse the concentrated smoke emitted by the smoke generator, providing a low velocity $(1 \mathrm{~m} / \mathrm{s})$, uniformly seeded ambient air around the research jet.

The flow following fidelity of the particles is critical in a supersonic flow investigation. The relaxation time of the alumina particles was computed to be $1.96 \mu$ s using the process outlined in reference [Melling 1997]. Similarly, the relaxation time for the oil droplets used to seed the ambient flow was determined to be $0.1 \mu \mathrm{s}$, which is significantly less than the alumina particles. Assuming Stokes drag law for a sphere, a numerical integration was then performed to compute the alumina particle relaxation distance to a step change in velocity across a shock. The distance for the alumina particles to reach $87 \%$ of the flow velocity was computed, yielding a relaxation distance of $2 \mathrm{~mm}$. The PIV subregions used to process the data were on the order of $2 \mathrm{~mm}$. Hence, the alumina particle relaxation in the jet core is masked by the spatial averaging caused by the subregions. The particle relaxation occurs over 1-2 subregions, which results in minimal smearing of the flow features for the data shown here.

\section{Results and Discussion}

Recall that for the Raman measurements, the entire square nozzle/plate assembly was rotated 90 degrees clockwise, looking upstream as shown in Figure 8. Raman measurements were acquired at several axial locations $(\mathrm{X}=12.7,38.1$, 63.5, 88.9, 114.3, 139.7, 330.2, and $381 \mathrm{~mm}$ ) coincident with the PIV and thermocouple measurement locations, but due to the time necessary to collect data at each spatial point (approximately 3-5 minutes), the total number of Raman measurement locations was limited to approximately 100 for a given run day. For the first axial measurement station, $X=12.7 \mathrm{~mm}$, upstream of the injector hole exit, the nozzle flow was not expected to vary in span ( $Z$ direction), therefore only a single line of data was collected along the centerline in the $Y$ direction. At each downstream axial location, a 6 (vertical) by 5 (spanwise) array of point measurement locations was utilized to map the flow behavior of the injector flow penetrating into and mixing with the nozzle exhaust. The $\mathrm{Y}, \mathrm{Z}$ locations of the points were determined by examining preliminary CFD solutions of the flow development and also Background Oriented Schlieren (BOS) images that were obtained for the center plane of all Set Points on the first day of the experiments, prior to any PIV or Raman data collection. The measurement grids for each Set Point are in general not identical. The $y / D$ range and $z / D$ spacing of the grid was altered depending on the anticipated cooling flow stream penetration. A sample measurement grid for one Set Point is given in Figure 12. At the beginning of a run day, background image spectra were recorded to provide a background spectra for baseline removal. Additionally, Rayleigh line spectra were acquired (by removing the RazorEdge long-pass filter) each run day for characterization of the instrument function. At each measurement station, 1000 single shot spectra were recorded. The data were processed as previously described, ensemble averaged and stored in Tecplot compatible file formats.

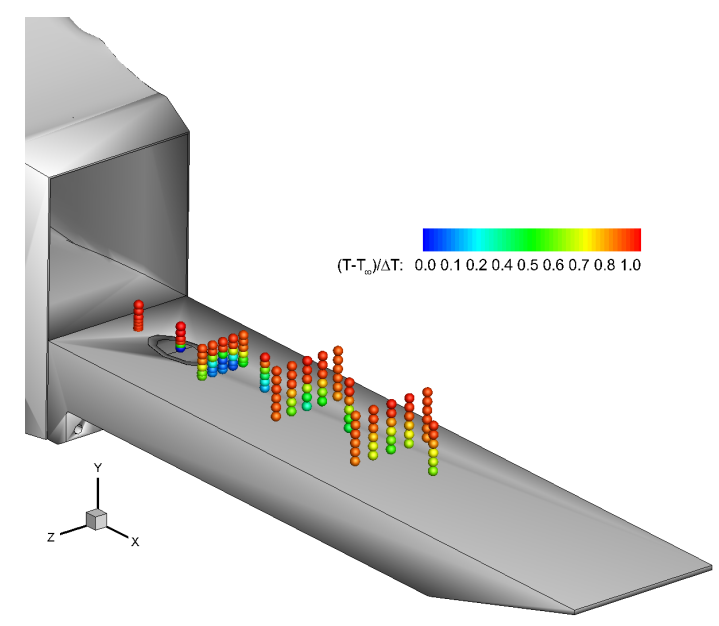


Figure 12. Nominal measurement grid and an example of Raman measured temperatures for Set Point 49, Br=1.0.

Temperature data were acquired over a wide range of flow temperatures and Mach numbers as listed in Table 1. In this paper, results for three of these conditions are presented: Set Points 23, 46 and 49, which are at Mach 0.376, 0.58 and 0.9 and temperature ratios of 1.77, 2.77 and 2.7, respectively. An ambient temperature point was acquired prior to the start of each run day using the Raman measurement system. These ambient temperatures and their rms temperature variations provide a check on the performance of the Raman measurements in the jet flow facility. The ambient temperatures were within a few degrees (2\%) of the ambient temperatures recorded using the SHJAR facility thermocouples mounted at the jet exit height in the facility. The rms temperature variations of the ambient temperature measured using the Raman thermometry system while the rig was running were $<3 \%$. Hence, the Raman diagnostic system installed in the SHJAR was able to produce accurate temperature measurements (while the rig was running), with $<3 \%$ rms levels in the quiescent ambient air. Any measurements in the jet flow will have this inherent measurement variation $\sigma_{R E}$ given by equation (1) added with the rms temperature variations in the jet flow.

Table 1 Operating Set Points with operating conditions.

\begin{tabular}{|c|c|c|c|c|c|c|}
\hline Set Point & TR & NPR & $\mathbf{M}_{\mathbf{j}}$ & $\begin{array}{c}\text { Blowing } \\
\text { Ratio } \\
(\mathbf{B r})\end{array}$ & $\begin{array}{c}\text { Nozzle } \\
\text { Mass Flow } \\
{\left[\mathbf{l b}_{\mathbf{m}} / \mathbf{s}\right]}\end{array}$ & $\begin{array}{c}\text { Injector } \\
\text { Mass Flow } \\
{\left[\mathbf{l b}_{\mathbf{m}} / \mathbf{s}\right]}\end{array}$ \\
\hline 23 & 1.765 & 1.103 & 0.376 & 0.5 & 1.16 & 0.0159 \\
\hline 23 & 1.765 & 1.103 & 0.376 & 1.0 & 1.16 & 0.0317 \\
\hline 23 & 1.765 & 1.103 & 0.376 & 2.0 & 1.16 & 0.0635 \\
\hline 27 & 1.765 & 1.36 & 0.677 & 0.5 & 2.09 & 0.0286 \\
\hline 27 & 1.765 & 1.36 & 0.677 & 1.0 & 2.09 & 0.0571 \\
\hline 42 & 2.7 & 1.066 & 0.304 & 0.5 & 0.76 & 0.0103 \\
\hline 42 & 2.7 & 1.066 & 0.304 & 1.0 & 0.76 & 0.0208 \\
\hline 46 & 2.7 & 1.227 & 0.548 & 0.5 & 1.37 & 0.0187 \\
\hline 46 & 2.7 & 1.227 & 0.548 & 1.0 & 1.37 & 0.0374 \\
\hline 49 & 2.7 & 1.692 & 0.900 & 0.5 & 2.25 & 0.0307 \\
\hline 49 & 2.7 & 1.692 & 0.900 & 1.0 & 2.25 & 0.0614 \\
\hline
\end{tabular}

In Table 1, The Set Points are the numbers corresponding to the jet acoustic measurement set point used in numerous other nozzle/jet tests that have been conducted in the AAPL. The other columns are as follows: TR= jet static temperature ratio (fully expanded jet static temperature divided by the ambient static temperature); NPR = nozzle pressure ratio (primary nozzle total pressure divided by ambient static pressure); $\mathrm{M}_{\mathrm{j}}=$ ideally expanded jet Mach number (assuming the

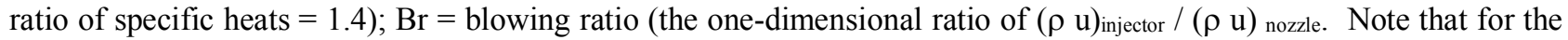
primary nozzle, the density and velocity are the expected fully expanded values at the nozzle exit. In the cooling air tube, the flow will have a significant boundary layer that will become "fully developed" in the quantity ( $\rho u)$. The ( $\rho \mathrm{u})$ injector is defined as the slug flow value of this quantity, simply determined by the mass flow through the tube divided by the tube cross sectional area; the next two columns are the expected mass flow rate through the primary nozzle and the prescribed flow rate through the injector tube needed to achieve the desired $\mathrm{Br}$. The primary nozzle flow rate shown in the table is calculated from the nozzle conditions and exit area, assuming a discharge coefficient of 1 . The injector flow rate was measured using a mass flow meter and controlled by a valve.

The SHJAR facility data acquisition system was used to record all of the rig operating temperatures and pressures during the testing. At the beginning of each data acquisition sequence (Raman or PIV) the rig settings were recorded. The average thermocouple readings of the embedded and surface mounted thermocouples were processed and tabulated. A sample set of thermocouple readings on the top and bottom of the plate for Set Point 23 , at $\mathrm{Br}=0.5$ are shown in Figure 13. 


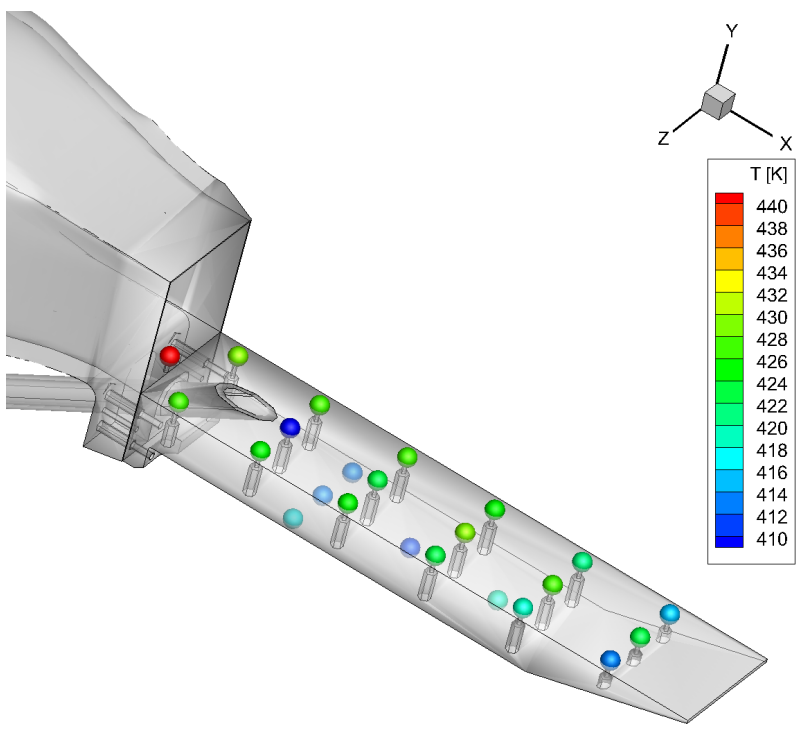

Figure 13: Location of thermocouples on the top and bottom of the plate. The recessed holes drilled from the bottom side of the plate to embed the top surface measurement thermocouples are shown in this translucent representation of the test article.

Both streamwise and cross-stream PIV data were collected across all of the Set Points listed in Table 1. The cross-stream PIV data at 15 planes were processed and merged into a single block of data and stored in Tecplot compatible file format. As mentioned in the data processing section, obtaining cross-plane vector maps without contamination from the model in the background is very difficult. The issue is exacerbated by the alumina seed material which coats the inside surfaces of the square nozzle and plate surface over time making them white and brighter in the background. The presence of the vertical sidewalls of the nozzle in the background results in regions of low signal to noise in the images, which causes spurious vectors in the processed vector maps. Three sample planes $(x / D=5,7,9)$ have been extracted from the Set Point $49, \mathrm{Br}=1.0$ case and are plotted as color contours of velocity magnitude with overlaid velocity vectors in Figure 14 . The spacing of the vectors in the image is $0.68 \mathrm{~mm}$. An example of the contamination/distortion in the processed data set, which occurs at the planes closest to the nozzle exit, is observed in Figure 14 at approximately $\mathrm{z} / \mathrm{D}=0.2$. These distortions are readily identified in the processed vector maps and should be ignored when evaluating the cross-stream PIV data. Initially the injected air plume has a significant vertical velocity component as the plume exits the injection tube. Further downstream at $x / D=7$, the jet in cross flow characteristic counter-rotating vortex pair is observed. At $x / D=9$, the plume has still not lifted off of the plate surface, however, there appears to be some counter-rotating vortices developing which will transport the heated ambient air underneath the plume. In Figure 15, the vorticity is plotted for the same planes plotted in Figure 14. The vorticity indicates that there is some recirculation near the bottom of the plume at $\mathrm{x} / \mathrm{D}=9$, however, the plume does not appear to be "lifted-off" from the plate.

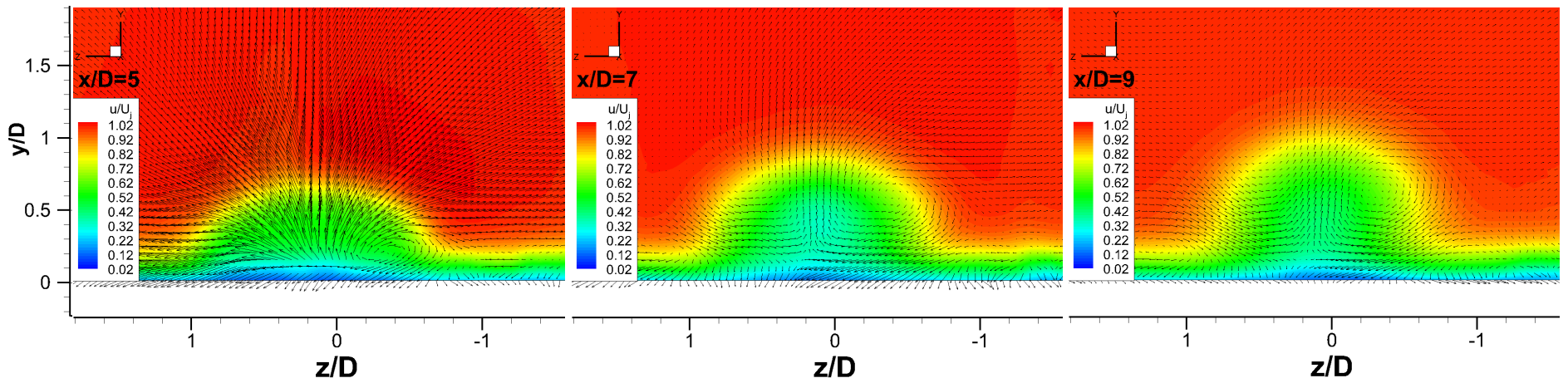

Figure 14: Cross-stream PIV results for the Set Point 49, $\mathrm{Br}=1.0$ case, at $\mathrm{x} / \mathrm{D}=5,7,9$. Color contours of velocity magnitude with velocity vectors overlaid on top. An artifact from the square nozzle lip is observed in the vector field for the $\mathrm{x} / \mathrm{D}=5$ case at $\mathrm{z} / \mathrm{D}=0.2$. 

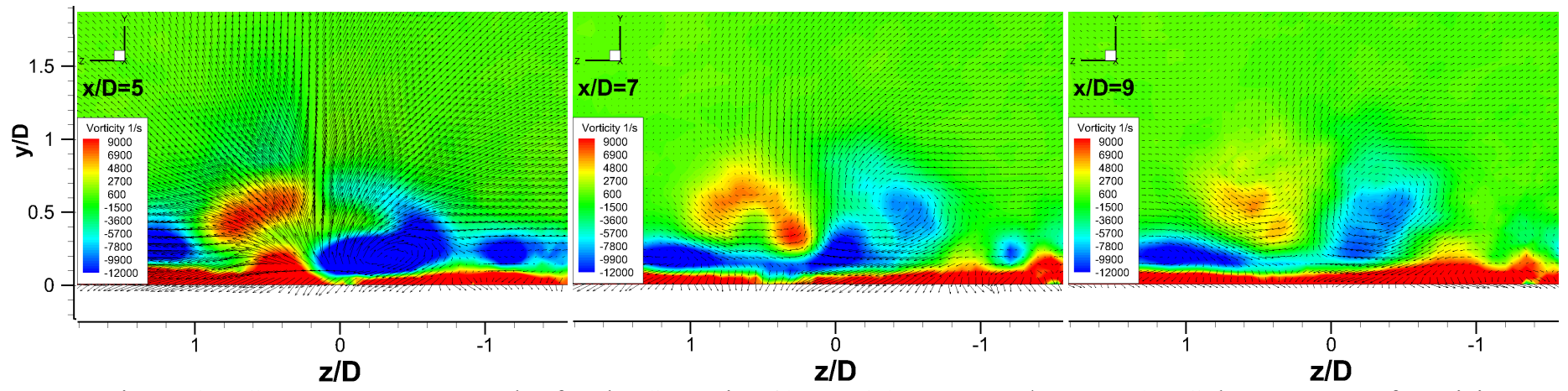

Figure 15: Cross-stream PIV results for the Set Point $49, \mathrm{Br}=1.0$ case, at $\mathrm{x} / \mathrm{D}=5,7,9$. Color contours of vorticity magnitude with velocity vectors overlaid on top. An artifact from the square nozzle lip is again observed in the vector field for the $\mathrm{x} / \mathrm{D}=5$ case at $\mathrm{z} / \mathrm{D}=0.2$.

For Set Point 23, data were acquired at $\mathrm{Br}=0.5,1.0$ and 2.0. Figure 16 shows vorticity plots with velocity vectors overlaid for Set Point 23 at all three blowing ratios at an axial distance of $x / D=7$. The color contour scale is the same for all three cases. At $\mathrm{Br}=2.0$, the cooling flow plume immediately lifts off and is never attached to the plate. At a $\mathrm{Br}=0.5$, there is some essence of a counter rotating vortex pair, but no hot cross-flow under the vortex. $\mathrm{At} \mathrm{Br}=1.0$, there is a weak counter rotating vortex pair, with a small amount of hot cross-flow under the plume. At $\mathrm{Br}=2.0$, the counter-rotating vortex pair is very strong and there is significant cross-flow of the heated ambient air under the injected plume of cooling air. The vortex cores at $\mathrm{Br}=2.0$ are nearly double the magnitude of the scale used in the color contour plots.
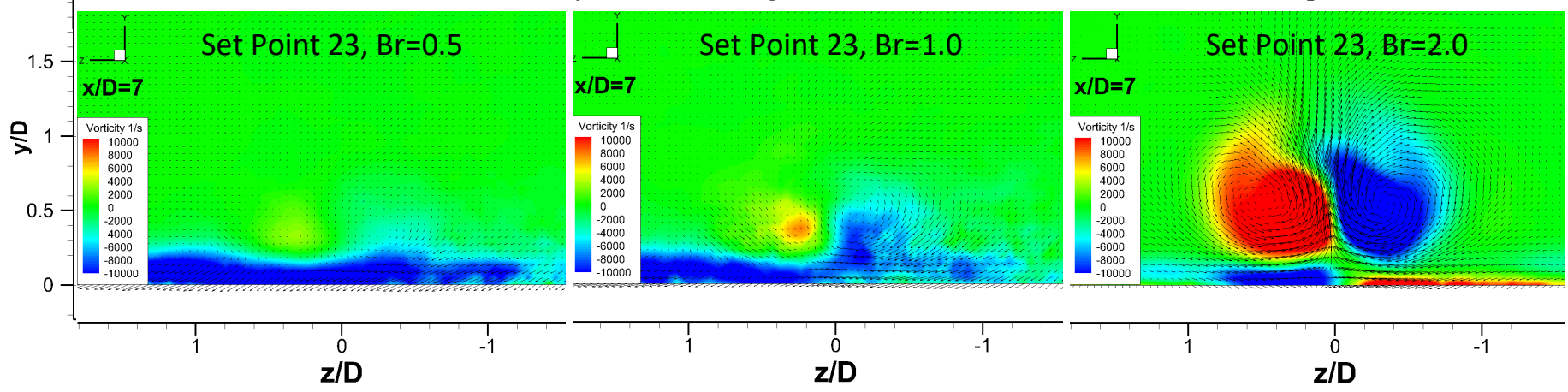

Figure 16: Contours of vorticity for Set Point 23, at $\mathrm{Br}=0.5,1.0,2.0$ at an axial station of $\mathrm{x} / \mathrm{D}=7$.

The streamwise PIV data were collected using an overhead light sheet which impinged on the plate. Flare light from the plate surface was blocked from reaching the cameras using a plate placed parallel with the surface of the plate. The plate was raised just high enough to attenuate the flare light from the $304.8 \mathrm{~mm}$ long plate surface. Again, as in the crossstream PIV data, the alumina seed material eventually coated the surfaces of the model with a white coating, increasing the amount of flare light being scattered. A sample set of streamwise PIV measurements normalized by the jet exit velocity $U_{\mathrm{j}}$ are shown in Figure 17 for Set Point 23 at all three blowing ratios. The data are placed in the model coordinate system and an $\mathrm{x}$-axis scale is shown at the bottom of the set of three. The transparent settings used to render the view of the model plate reveal the axial locations of the embedded thermocouples, in Figure 17. In addition, the injection tube is visible inside the plate and the inside diameter of the tube is also denoted by the enhanced black lines. The center of the injection hole is at $x / D=3$. The data next to the square nozzle exit are contaminated by the flare light from the model. The contours of velocity magnitude clearly show that at a $\mathrm{Br}=0.5$, the low velocity injected flow is attached to the plate. At $\mathrm{Br}=1.0$, the low velocity injected plume lifts off the plate at around $\mathrm{x} / \mathrm{D}=7$, where high speed fluid is now observed below the injected air plume. At $\mathrm{Br}=2$, the velocity of the injected air plume is higher than the free stream flow and is never attached to the plate and is clearly above the plate. Low velocity, higher temperature fluid has filled in underneath the plume. 


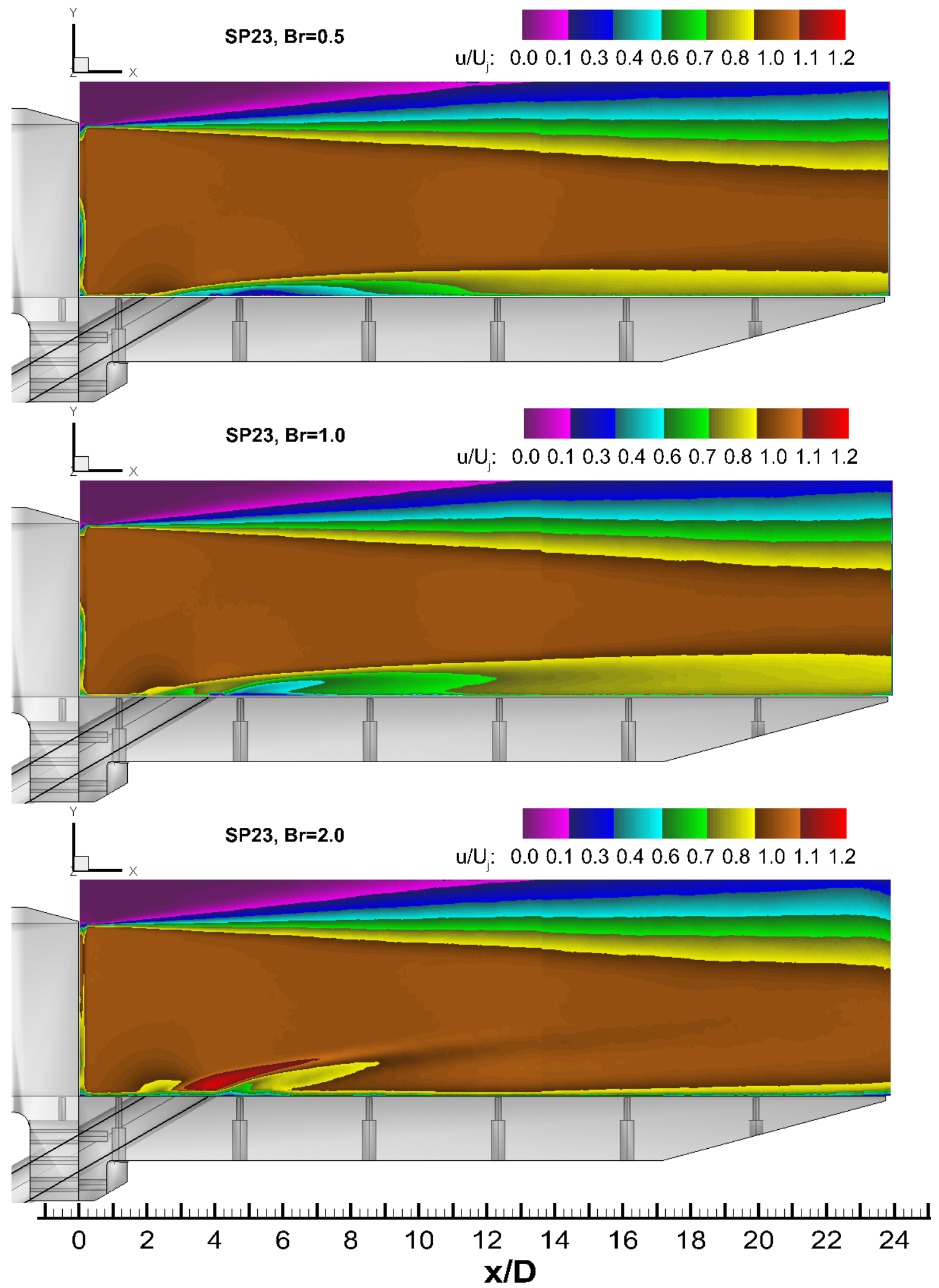

Figure 17: Streamwise PIV velocity contours normalized by the jet exit velocity $U_{j}$ for Set Point 23 at 3 different blowing ratios: $\mathrm{Br}=0.5,1.0,2.0$. The inside diameter of the injector tube is also denoted by the enhanced black lines. The embedded thermocouple locations are visible in the rendering of the plate, as well as the injection tube location. 
The data in Figure 17 can also be plotted as line profiles to offer a different perspective on the data, as shown in Figure 18. Line profiles along the plate centerline are extracted at the same axial stations where Raman data were collected. The line plots clearly illustrate the growth of the shear layer and the collapse of the core region of the flow as the top shear layer moves in. Near the plate the $\mathrm{Br}=0.5$ case shows the distortions to the flow near the plate from the injected air plume, but the flow remains attached to the surface. The same trends of injection flow behavior when varying the blowing ratio are visible, as was the case in the previous discussions of PIV derived flow contours. Namely, in the $\mathrm{Br}=1.0$ case, the inflections in the velocity profile near the plate indicate the injected air plume has slightly lifted off of the plate. The $\mathrm{Br}=2.0$ case profiles show that the plume was never attached to the plate and its height above the plate increases with axial distance.
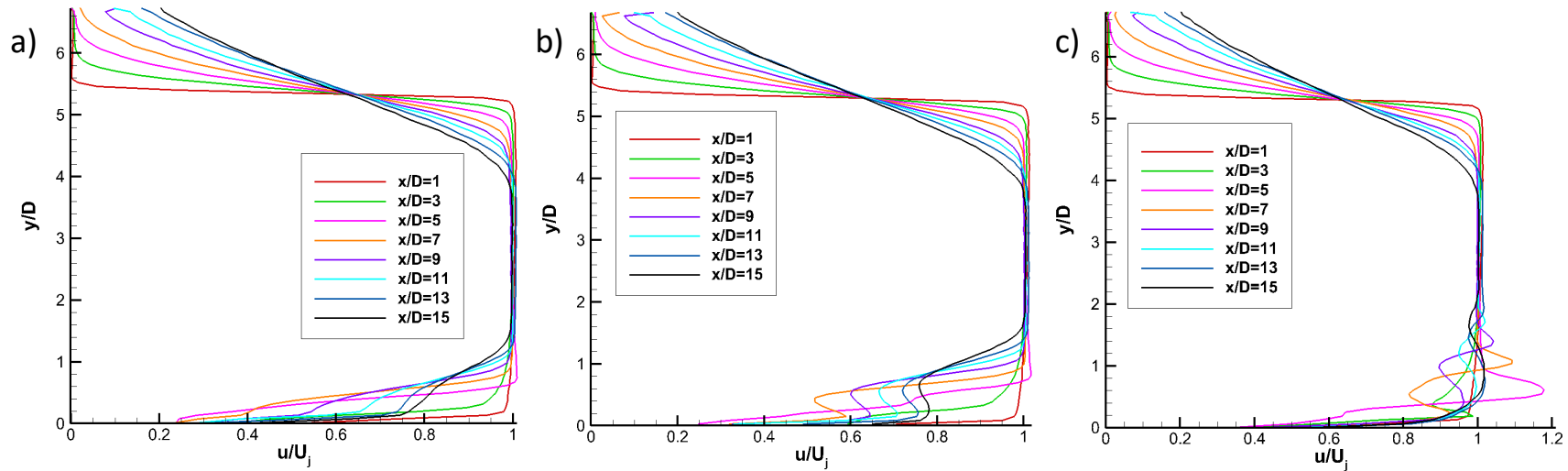

Figure 18: Velocity line plots of the Set Point 23: a) $\mathrm{Br}=0.5$, b) $\mathrm{Br}=1.0$, c) $\mathrm{Br}=2.0$ cases on the plate centerline. The line profiles correspond to the planes where the Raman temperature data were collected.

The Raman temperature diagnostic data were processed for all of the grid locations across all of the Set Points in Table 1. Attempts were made to acquire Raman temperature measurements as close to the plate surface as possible. The Raman spectra acquired at $y / \mathrm{D}=0.02-0.1$ were significantly dominated by the (Rayleigh/laser line) flare light off of the plate surface. In Figure 19 Raman temperature profiles along the centerline of the plate are presented for the three blowing ratios in Set Point 23. The temperature profiles are non-dimensionalized by subtracting the ambient temperature $\mathrm{T}_{\infty}$ and then dividing by the temperature difference between the jet exit temperature and the ambient temperature $\Delta \mathrm{T}=\left(\mathrm{T}_{\mathrm{j}}-\mathrm{T}_{\infty}\right)$. The profiles are plotted for increasing values of $\mathrm{x} / \mathrm{D}$. Values of $\mathrm{x} / \mathrm{D}$ with a subscript indicate data sets that were acquired on subsequent run days in order to fill in the range of the temperature profiles for vertical positions that were closer to the wall than were originally believed to be feasible. The profiles at $x / D=1$ indicate small thermal boundary layers can barely be resolved by the Raman system for the near plate measurements. At $\mathrm{x} / \mathrm{D}=3$, which is directly above the center of the injection hole, the injected air temperature is clearly measured below $\mathrm{y} / \mathrm{D}=0.2$ for the $\mathrm{Br}=0.5$ and 1.0 cases and below $\mathrm{y} / \mathrm{D}=0.4$ for the $\mathrm{Br}=2.0$ case. At $\mathrm{x} / \mathrm{D}=5$, the cool injected air is still down near the plate surface. Unfortunately, data were not collected below $\mathrm{y} / \mathrm{D}=0.2$ for the $\mathrm{Br}=0.5$ and 1.0 cases, which would have showed the low temperature continuing down along the plate surface. For the $\mathrm{Br}=2.0$ case at $\mathrm{x} / \mathrm{D}=5$, the coolest injected air temperature is measured at $\mathrm{y} / \mathrm{D}=0.6$, and then the temperature increases closer to the plate, indicating that the hot freestream air is being transported under the lifted off cooling plume. At $\mathrm{x} / \mathrm{D}=7$, the temperature of the air at $\mathrm{y} / \mathrm{D}=0.3$ is increasing as the injected air mixes and absorbs heat from the surrounding hot air. The trend of increasing jet plume temperature continues with increasing distance downstream, with all of the profiles asymptotically approaching the main square nozzle gas temperature. In the $\mathrm{Br}=1.0$ case, the plume projects higher into the main flow stream and the cold injected air temperatures are measured in the $x / D=5$ profile down at $y / D=0.3$. At increasing axial distances the $\mathrm{Br}=1.0$ case temperature profiles are again observed to increase as the plume mixes/transfers heat with the surrounding heated jet plume. All of the profiles again asymptotically approach the main heated flow stream temperature. Data sets acquired on different run days were corrected by using the ambient temperature on the run day. In general it is most desirable to acquire a single Set Point in one day so that the jet exit temperature is consistent, since $T_{j}$ is set as a ratio relative to the ambient temperature.

The bottom two plots in Figure 19 are the normalized Raman temperature profiles along with normalized velocity profiles extracted from the streamwise PIV data sets at the same axial locations as the Raman temperature profiles at $\mathrm{Br}=2.0$. For the $\mathrm{Br}=2.0$ case the temperature above the injection hole $(\mathrm{x} / \mathrm{D}=3)$ again drops down to the injected air temperature. The peak in the velocity profile at $\mathrm{x} / \mathrm{D}=3$ occurs at this minimum temperature point, $\mathrm{y} / \mathrm{D}=0.2$, indicating the center of the injected air plume. At $\mathrm{x} / \mathrm{D}=5$, the temperature drops down to the injected air temperature at $\mathrm{y} / \mathrm{D}=0.6$ and then climbs back up to $340 \mathrm{~K}$ at $\mathrm{y} / \mathrm{D}=0.3$, clearly indicating that the injected cold air plume is well above the plate and the warm surrounding hot air is filling in below the injection plume. The minimum air temperature measured in the $\mathrm{x} / \mathrm{D}=5$ profile at $y / D=0.6$ matches the peak velocity in the injected air plume shown in the velocity profile plot to the right. The temperature profiles at increasing axial distance all exhibit an inflection point where the profile passes through the center of the increasingly higher temperature injected air plume. The width of the plume is growing as denoted by the broadening 
of the inflection well in the temperature profiles. Far downstream the gas temperatures near the plate are again approaching the free stream heated air flow temperatures. If Raman temperature measurements had been acquired closer to the plate than $\mathrm{y} / \mathrm{D}=0.3$, we expect that the temperature inversions observed in the $\mathrm{Br}=2.0$ case, indicative of a lifted off plume, would have been observed in the other two $\mathrm{Br}$ cases.
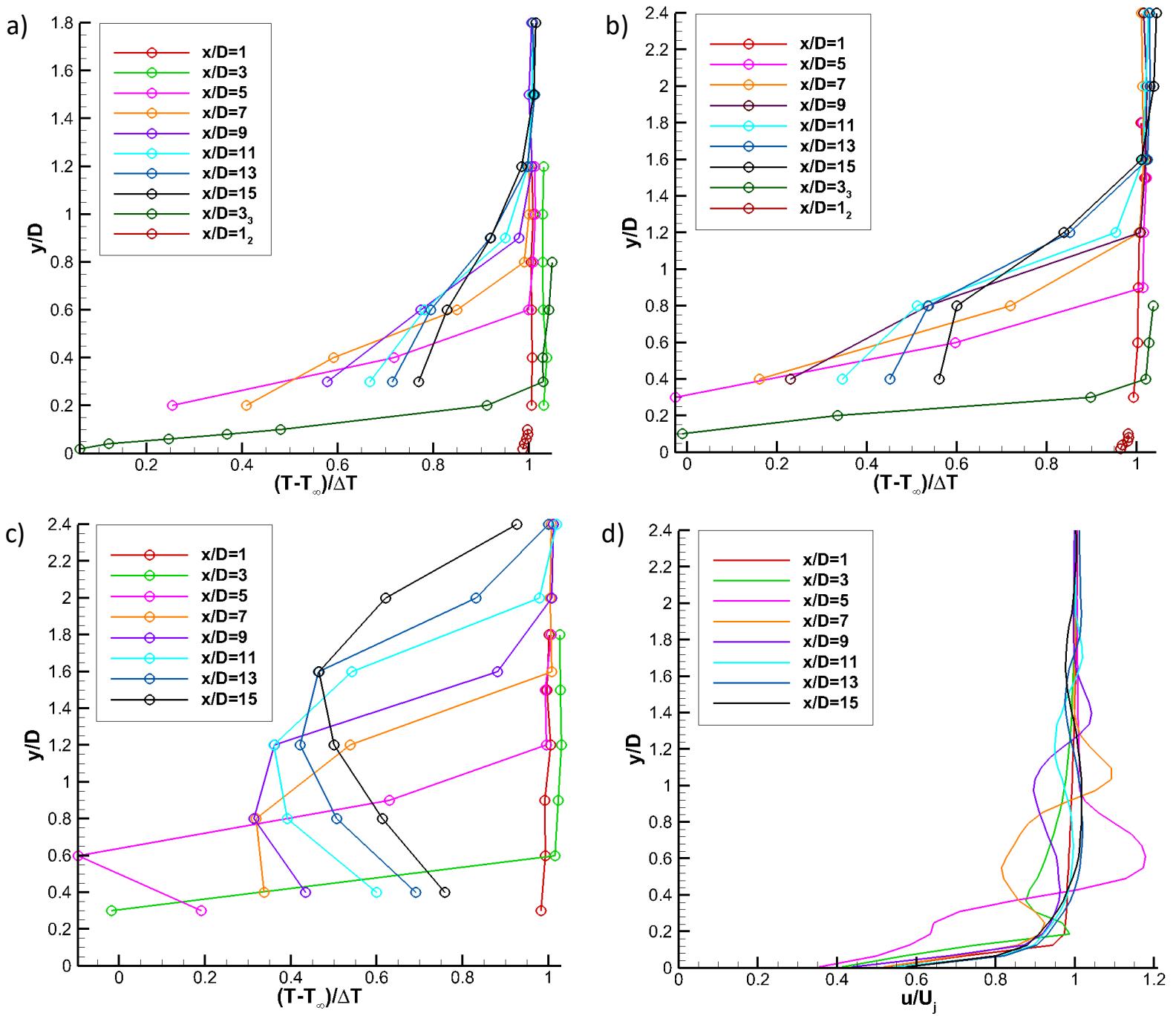

Figure 19: Centerline Raman temperature profiles for Set Point 23: a) $\mathrm{Br}=0.5, \mathrm{~b}) \mathrm{Br}=1.0$ and c) $\mathrm{Br}=2.0$. The bottom right plot (d) is the centerline PIV velocity profile for $\mathrm{Sp} 23, \mathrm{Br}=2.0$, corresponding to the temperature profile directly to the left (c).

The non-dimensionalized Raman centerline temperature profiles for Set Points 27, 42 and 46 for blowing ratios of 0.5 and 1.0 are shown in Figure 20. Here the main observation is that clearly the injected air plume remains attached to the surface for the $\mathrm{Br}=0.5$ cases. At the $\mathrm{x} / \mathrm{D}=5$ locations, the profiles show the injected air is at the plate surface and remain there. For the $\mathrm{Br}=1.0$ cases, the temperature profiles indicate that the injected air plumes are lifting off of the plate surface, as depicted by the inflection of the profiles at $\mathrm{x} / \mathrm{D}=5$. The increasing temperature near the plate confirms that ambient heated air is filling in under the cold air injection plume. The Raman temperature profiles at increasing axial distance again asymptotically approach the main jet flow temperature.

The non-dimensionalized Raman temperature profiles for Set Point 49 at blowing ratios of 0.5 and 1.0 are shown in Figure 21. The trends observed in these two blowing ratios at this higher Mach number, high temperature ambient condition are similar to those observed in Figure 20. One feature that is different is that the ambient jet temperature measured at the furthest downstream locations is no longer reaching the hot jet exit temperature. At this Set Point the shear layer from above is closing in on the jet core collapsing the high temperature core region earlier than in the lower Mach number Set Point cases. This effect is somewhat evident also in the Set Point 42 case shown in Figure 20. 
a)

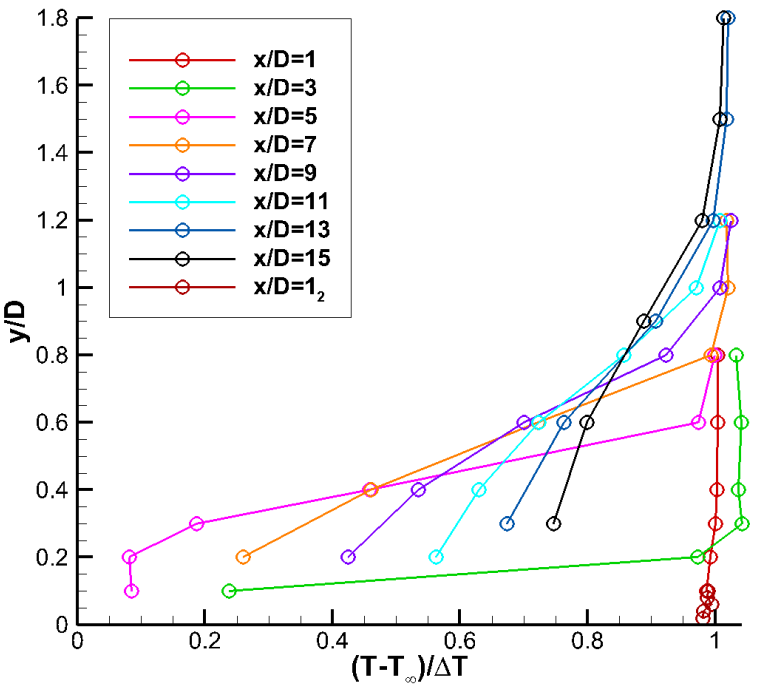

c)

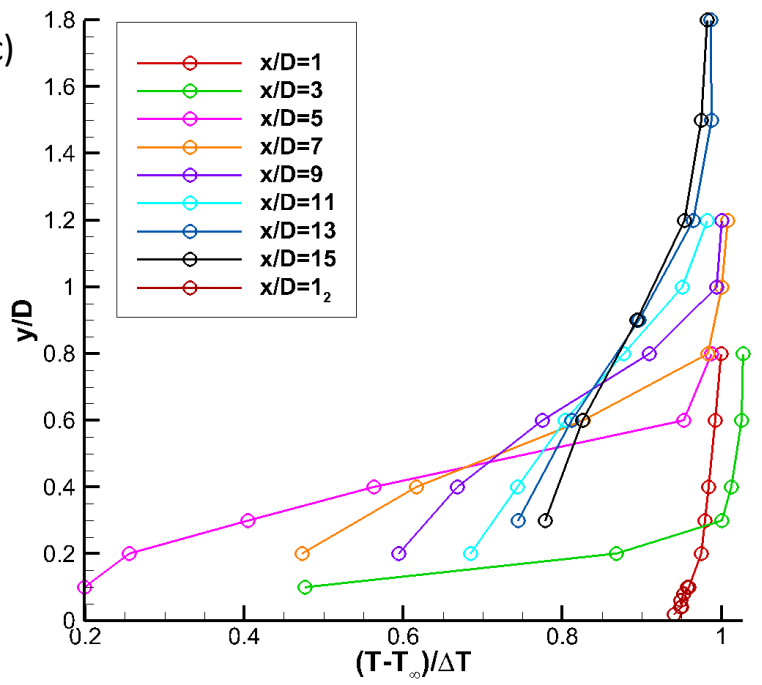

b)

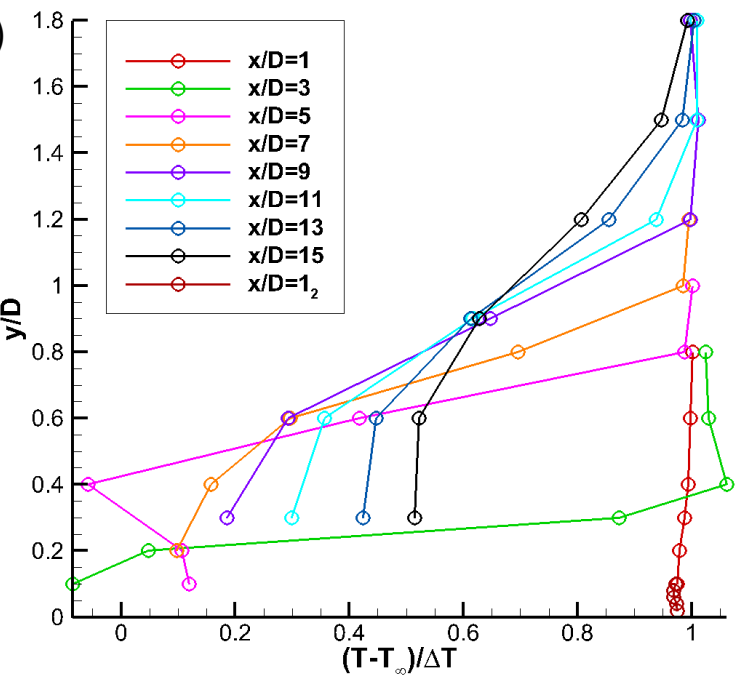

d)

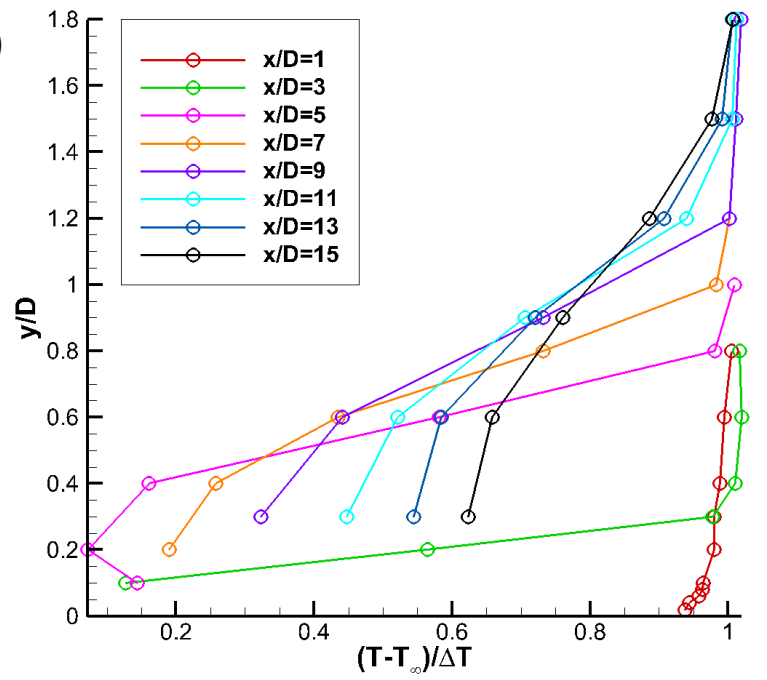

f)

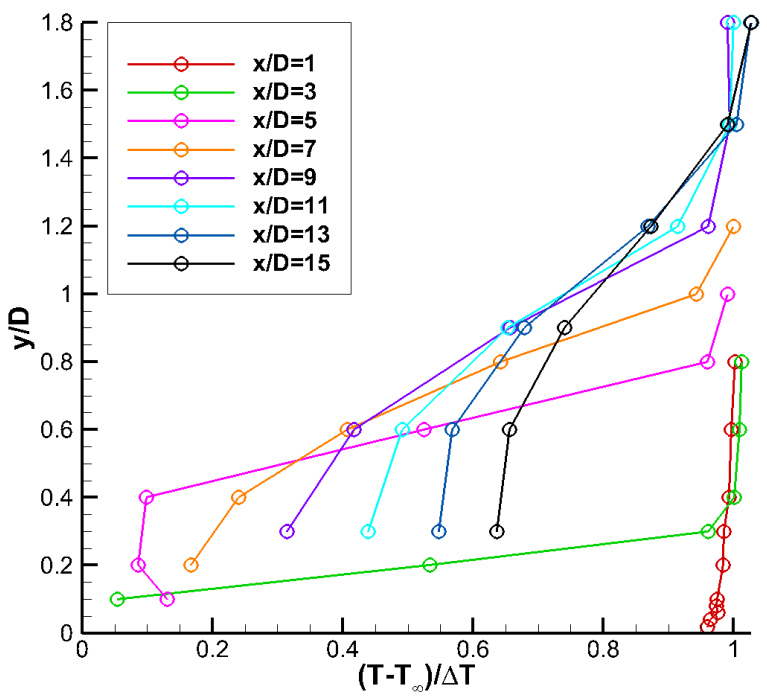

$\left(\mathbf{T}-\mathbf{T}_{s}\right) / \Delta \mathbf{T}$

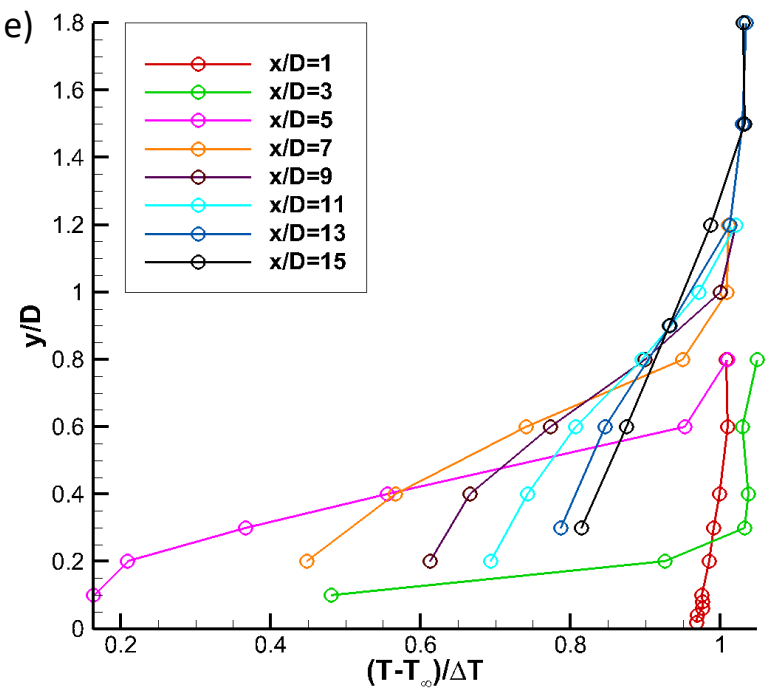

Figure 20: Centerline Raman non-dimensional temperature profiles for: a) Set Point 27, $\mathrm{Br}=0.5, \mathrm{~b}$ ) Set Point 27, $\mathrm{Br}=1.0$, c) Setpoint 42, $\mathrm{Br}=0.5$, d) Set Point 42, $\mathrm{Br}=1.0$, e) Set Point 46, $\mathrm{Br}=0.5$, f) Set Point 46, $\mathrm{Br}=1.0$. 
a)

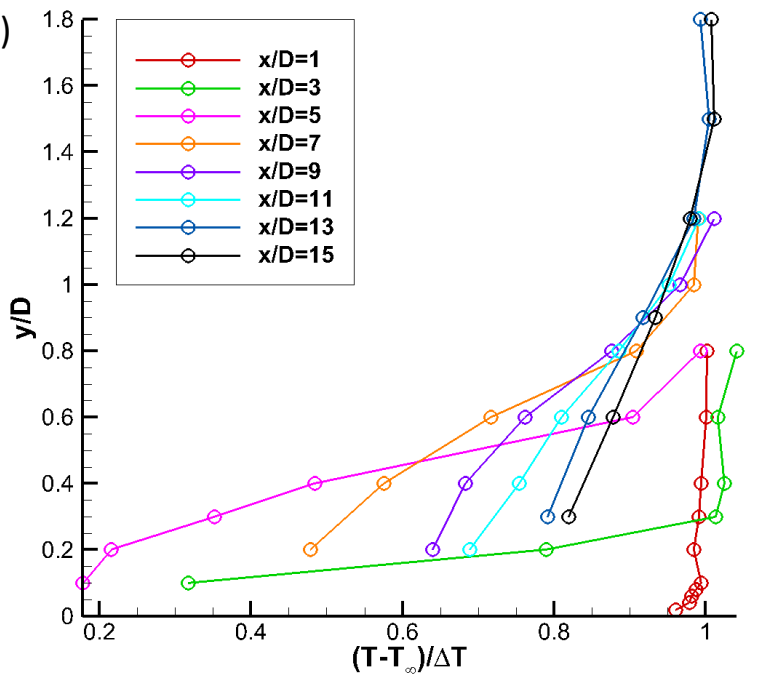

b)

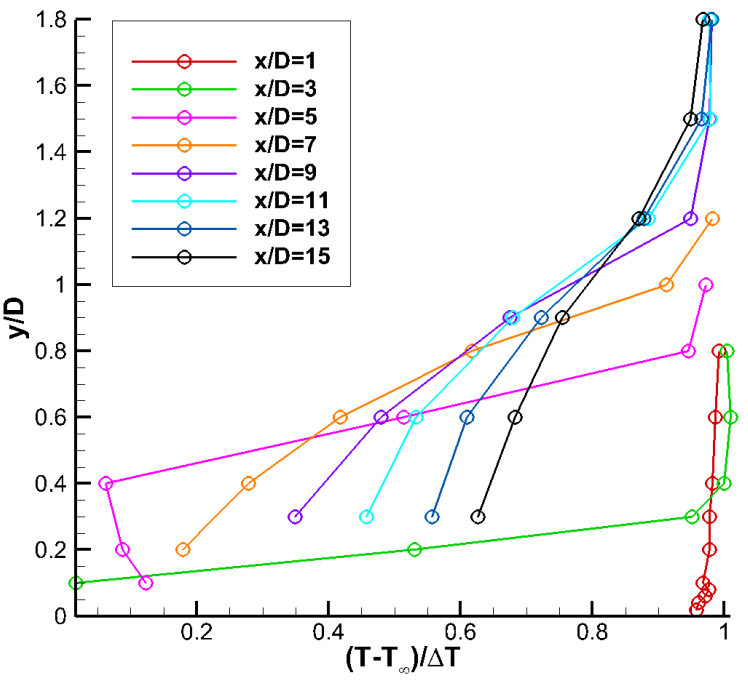

Figure 21: Raman measured non-dimensional temperature profiles along the plate centerline for the Set Point 49 case at a) $\mathrm{Br}=0.5$ and b) $\mathrm{Br}=1.0$.

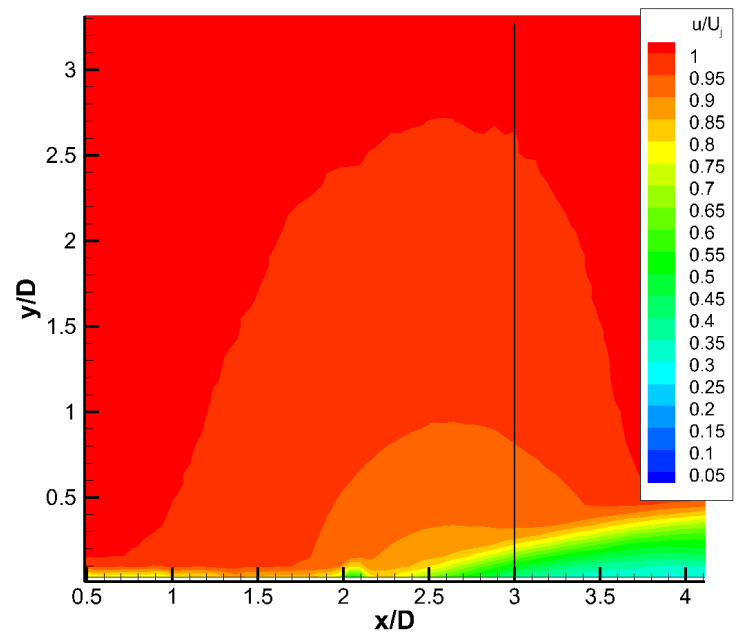

Figure 22: Velocity magnitude along the centerline of the nozzle/plate flow for the Set $\mathrm{Point} 49, \mathrm{Br}=1.0$ case. The center of the injection hole is at $\mathrm{x} / \mathrm{D}=3$. The vertical line is drawn through the stagnation region that develops upstream and above the injection plume.

A common feature observed in all of the temperature profiles is at $x / D=3$, where an overshoot of the temperature occurs directly above the injection hole in the range $0.3<\mathrm{y} / \mathrm{D}<0.7$. The temperature in this region exceeds the nominal jet exit temperature by approximately $12-14 \mathrm{~K}$. The overshoot gradually declines and at about $\mathrm{y} / \mathrm{D}=0.7$ the temperature is back down to the main flow jet exit temperature. This temperature overshoot was observed in all of the Raman temperature profiles, regardless of Mach number. A centerline velocity profile extracted from the streamwise PIV data set at $\mathrm{x} / \mathrm{D}=3.0$, illustrates that there is a stagnation region in the flow upstream and above the cold air injection plume, see Figure 22. Similar stagnation regions were observed in the Set Point 23 streamwise velocity contours shown in Figure 17. The stagnation region for Set Point $49, \mathrm{Br}=1.0$ at $\mathrm{x} / \mathrm{D}=3$ shows a drop in velocity magnitude beginning at $\mathrm{y} / \mathrm{D}=0.3$ and extending up until $\mathrm{y} / \mathrm{D}=0.7$. The velocity drops from $512 \mathrm{~m} / \mathrm{s}$ at $\mathrm{y} / \mathrm{D}=2.5$ down to $464 \mathrm{~m} / \mathrm{s}$ at $\mathrm{y} / \mathrm{D}=0.3$, which results in a rise in the measured temperature. An estimate for the temperature rise can be computed using the relation between the total and the static temperatures:

$$
T_{t}=T_{s}\left(1+\frac{\gamma-1}{2} M^{2}\right)
$$

where $\gamma$ is the ratio of specific heats. After some manipulation the more useful expression is obtained for the change in temperature resulting from a change in velocity of the gas:

$$
T_{2}-T_{1}=\frac{\gamma-1}{2 \gamma R}\left(V_{1}^{2}-V_{2}^{2}\right)
$$


where $R$ is the gas constant and $\mathrm{T}_{1}$ and $\mathrm{V}_{1}$ are the upstream conditions and $\mathrm{T}_{2}$ and $\mathrm{V}_{2}$ are the downstream conditions. Inserting the velocity values above and using $\gamma=1.37$, obtained from computations from the rig settings, the estimated temperature rise is $T_{2}-T_{1}=22 \mathrm{~K}$. The estimated temperature rise is approximately $30 \%$ higher than the temperature rise measured in the flow.

Collecting 1000 Raman spectra at each measurement point enables the computation of both the mean temperature and the rms variation in the temperature. The rms temperature variations are expected to be comparable to the flow turbulence properties measured via PIV. The rms temperature estimates have been corrected $\left(\mathrm{T}^{\prime}{ }_{\mathrm{c}}\right)$ using equation 2 to remove the inherent systematic variation in the Raman temperature measurement technique, leaving only contributions from random measurement error and flow turbulence. The centerline rms temperatures normalized by the temperature difference $\Delta \mathrm{T}$, which is the difference between the average jet exit temperature measured using the SHJAR plenum thermocouples and the ambient temperature measured from the facility thermocouples, averaged over the entire Set Point run. These normalized variations in the rms temperature are plotted in Figures 23-26 for two blowing ratios for Set Point 23 and 49. Also included in the figures are the normalized temperature profiles presented earlier for these cases as well as the flow turbulence intensity $\left(\mathrm{u}^{\prime} / \mathrm{U}_{\mathrm{j}}\right)$ and the normalized velocity profiles $\left(\mathrm{u} / \mathrm{U}_{\mathrm{j}}\right)$ at the same locations in the flow as the Raman temperature profiles. The peak rms fluctuations in temperature appear to occur at the top of the thermal interface between the cold injection air and the heated main flow stream. Generally, the rms temperatures peak at the same $y / D$ coordinate as the flow turbulence and exhibit a similar broadening of the shearing interface between the cold and hot flow streams with increasing distance downstream. For the Set Point $23, \mathrm{Br}=0.5$ case shown in Figure 23, the peaks in the rms temperature at the different $\mathrm{x} / \mathrm{D}$ closely match the peaks in the turbulence intensity. All of the PIV velocity profiles display the slowdown in the freestream velocity above the injection cooling hole at $x / D=3$ due to the blockage of the injected flow.
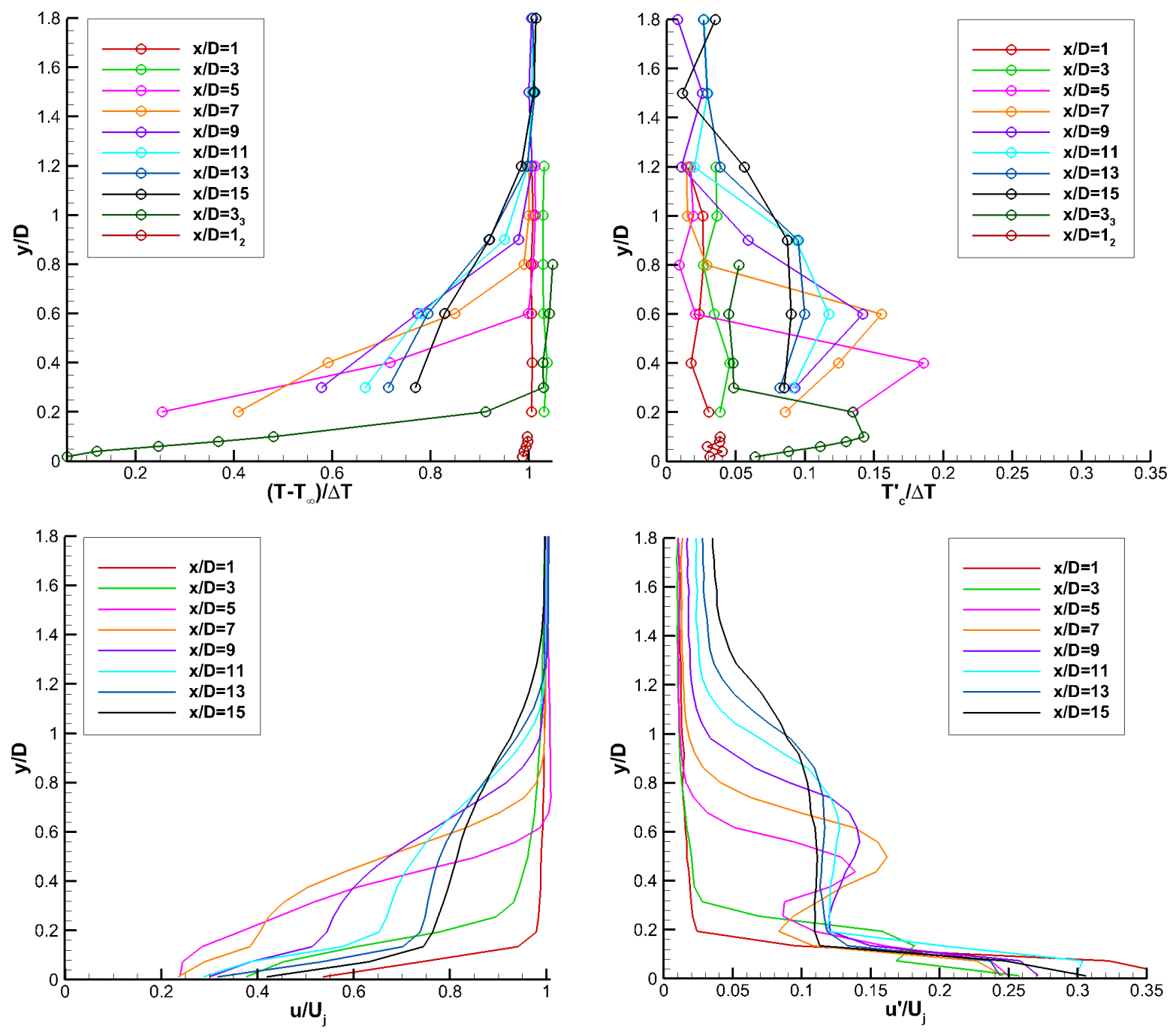

Figure 23: Normalized mean and rms temperature profiles measured via Raman scattering and PIV normalized velocity and turbulence profiles for Set Point 23, $\mathrm{Br}=0.5$. 
The Set Point 23, $\mathrm{Br}=2.0$ case rms temperatures and flow turbulence profiles are shown in Figure 24. The air injection plume is well above the plate surface, as observed in the $\mathrm{u}^{\prime} / \mathrm{U}_{\mathrm{j}}$ profile at $\mathrm{x} / \mathrm{D}=5$, which peaks at approximately $\mathrm{y} / \mathrm{D}=0.8$. The rms temperature peaks at approximately $\mathrm{y} / \mathrm{D}=0.9$. A similar trend is observed for the remaining profiles. The rms temperatures are peaking higher above the plate than the flow turbulence levels in the injected air mixing region/shear layer. The normalized rms temperature values are approximately the same as the flow turbulence values away from the plate in the jet freestream.
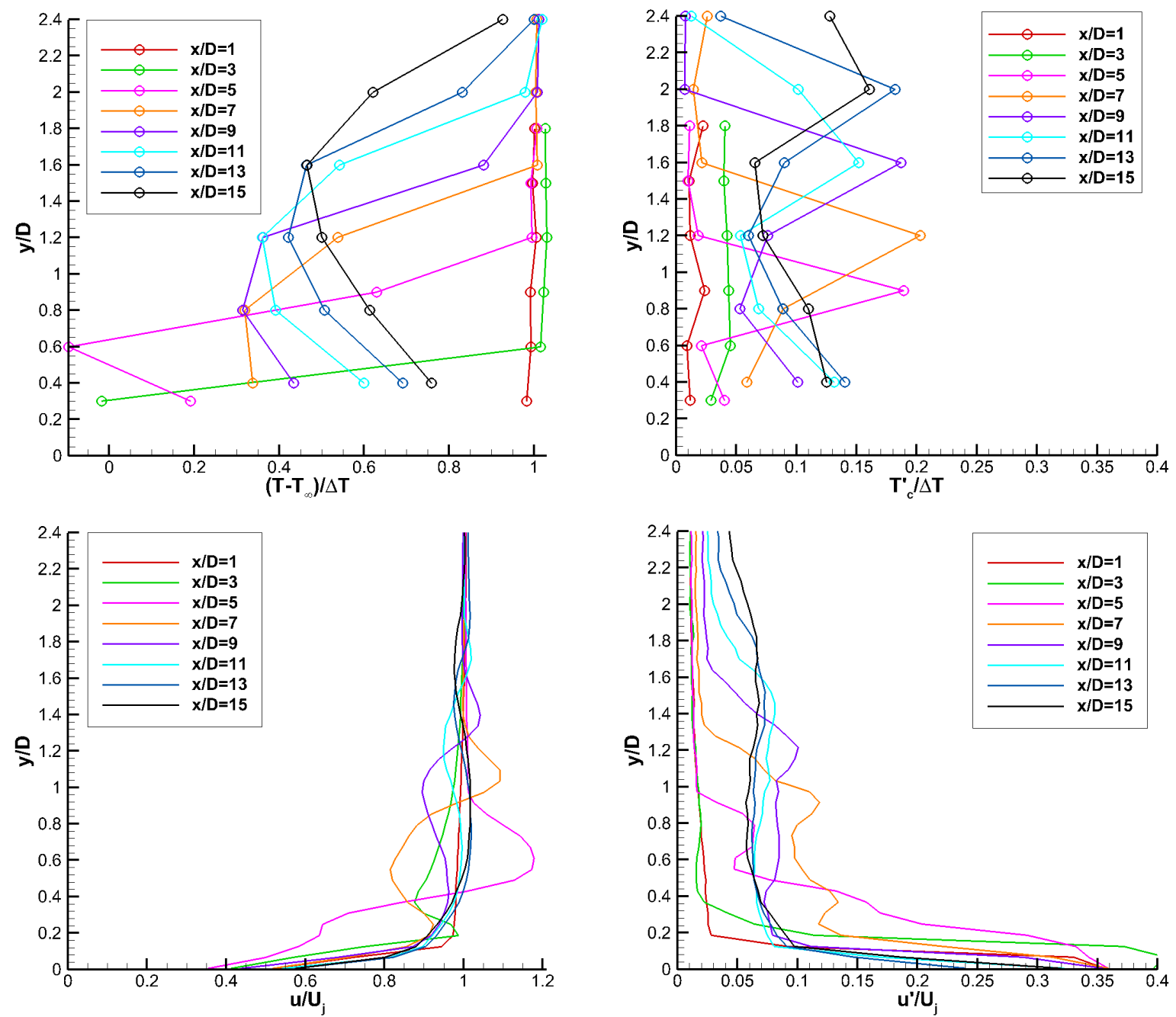

Figure 24: Normalized mean and rms temperature profiles measured via Raman scattering and PIV normalized velocity and turbulence profiles for Set Point 23, $\mathrm{Br}=2.0$.

The Set Point 46 profiles for a $\mathrm{Br}=0.5$ are shown in Figure 25, where again the trend is for the thermal shear layer to not have the same decay rate nor the same peak location as the momentum shear layer. The normalized rms temperature values are slightly higher than the flow turbulence values away from the plate in the jet freestream. The Set Point 49 profiles for a $\mathrm{Br}=0.5$ are shown in Figure 26 with similar features to the Set Point 46 profiles shown in Figure 25. 

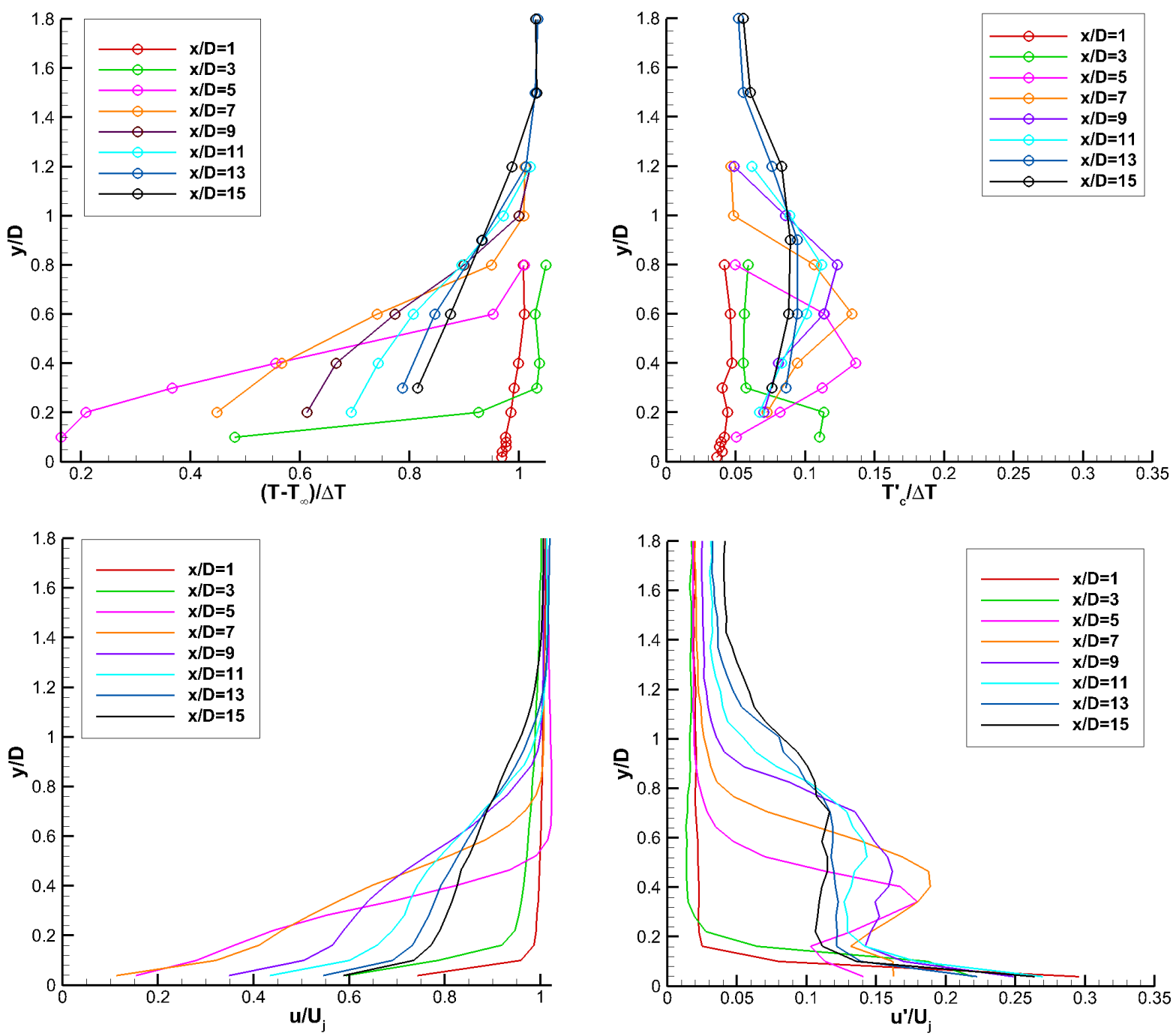

Figure 25: Normalized mean and rms temperature profiles measured via Raman scattering and PIV normalized velocity and turbulence profiles for Set Point $46, \mathrm{Br}=0.5$. 

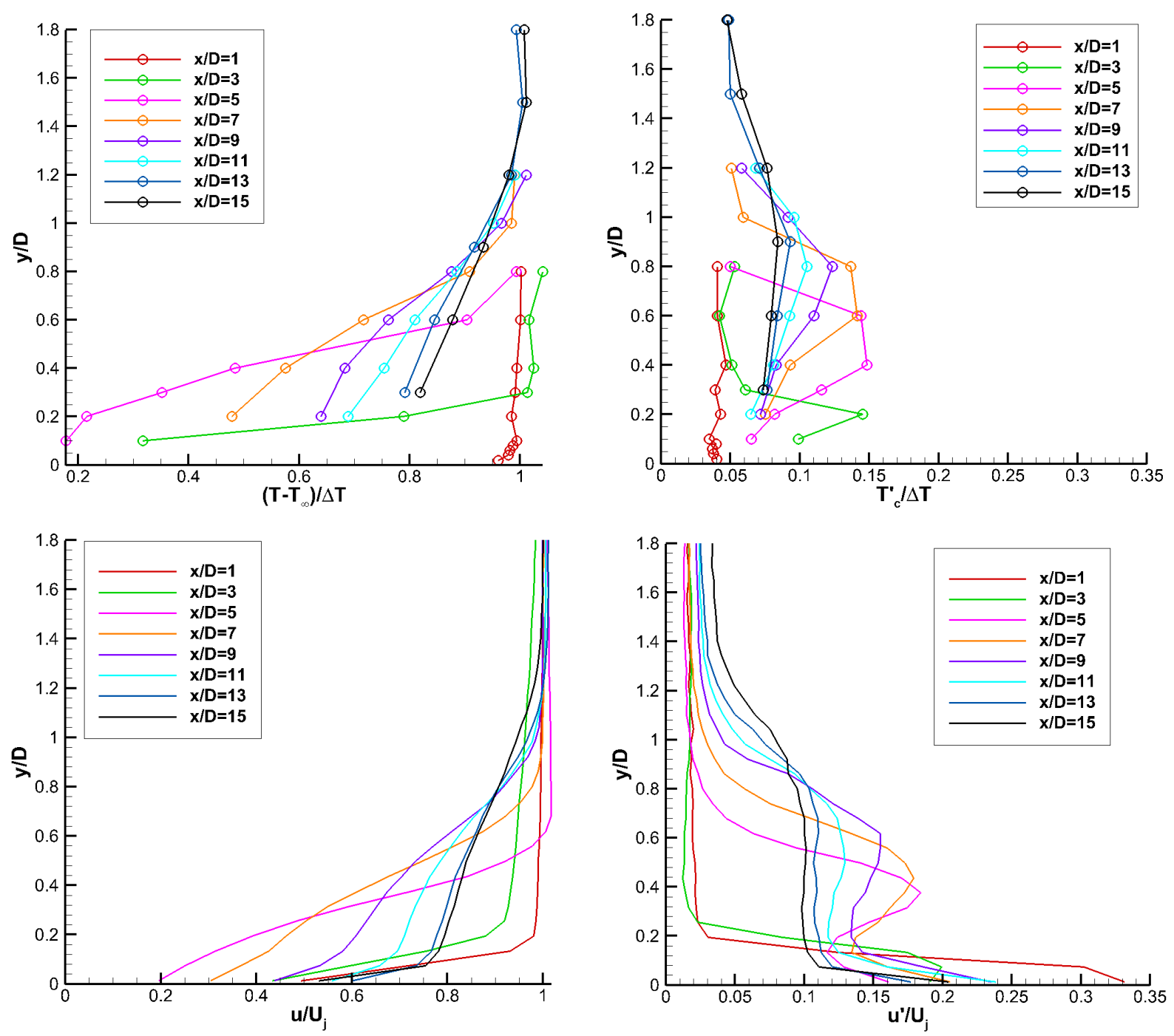

Figure 26: Normalized mean and rms temperature profiles measured via Raman scattering and PIV normalized velocity and turbulence profiles for Set Point 49, $\mathrm{Br}=0.5$.

The Set Point 49, $\mathrm{Br}=1.0$ profiles are plotted in Figure 27, where initially the thermal and momentum shear layers peak at the same height above the plate $(\mathrm{y} / \mathrm{D}=0.2)$. However, with increasing axial distance the rms temperatures peak higher above the plate than the peak turbulence in the shear layer between the injected air plume and the ambient flow stream. The difference in the peak locations above the plate are nominally $0.1 \mathrm{y} / \mathrm{D}$. Generally the Raman rms temperature profiles exhibit very similar character to the PIV flow turbulence profiles for all of the cases presented. The initially thin shear layer grows in thickness and height above the plate with increased distance downstream from the injection point. The normalized rms temperature values are slightly higher than the flow turbulence values away from the plate in the jet freestream. The velocity profiles illustrate the velocity inside the plume is relatively uniform, and then accelerates back up to the freestream flow above the plume. The Set Point $49, \mathrm{Br}=1.0$ case and SetPoint $46, \mathrm{Br}=0.5$ case are the only instances where the flow turbulence levels are significantly higher than the normalized rms temperature fluctuations. The turbulence intensities over the range $3<\mathrm{x} / \mathrm{D}<7$ peak at approximately 0.2 , while the normalized rms temperatures exhibit peaks of approximately 0.14 over the same $\mathrm{x} / \mathrm{D}$ range.

In the description of the Raman diagnostic system, the dimensions of the probe volume were presented, which were nominally $70 \mu \mathrm{m}$ diameter and $6 \mathrm{~mm}$ long cylinder. Fortunately, the Raman system was configured so that the laser beam and hence the $6 \mathrm{~mm}$ length of the probe volume, was parallel to the plate and in the spanwise direction. The temperature gradients measured along the centerline were primarily perpendicular to the plate surface, spanning the $70 \mu \mathrm{m}$ diameter of the Raman probe volume. Due to the long probe volume length, there was some concern that the Raman data may suffer from a small amount of low pass filtering of the turbulent temperature fluctuations in the flow. The extended length of the probe volume does yield a small amount of spatial averaging, which results in a slight under prediction of the peak rms fluctuations in the gas temperature, mostly in the region of the injection point of the plume $(\mathrm{x} / \mathrm{D}=3)$, where the plume 
radius of curvature is smallest. Generally, no significant differences between the flow turbulence levels and the normalized rms temperatures were observed in the data collected here.
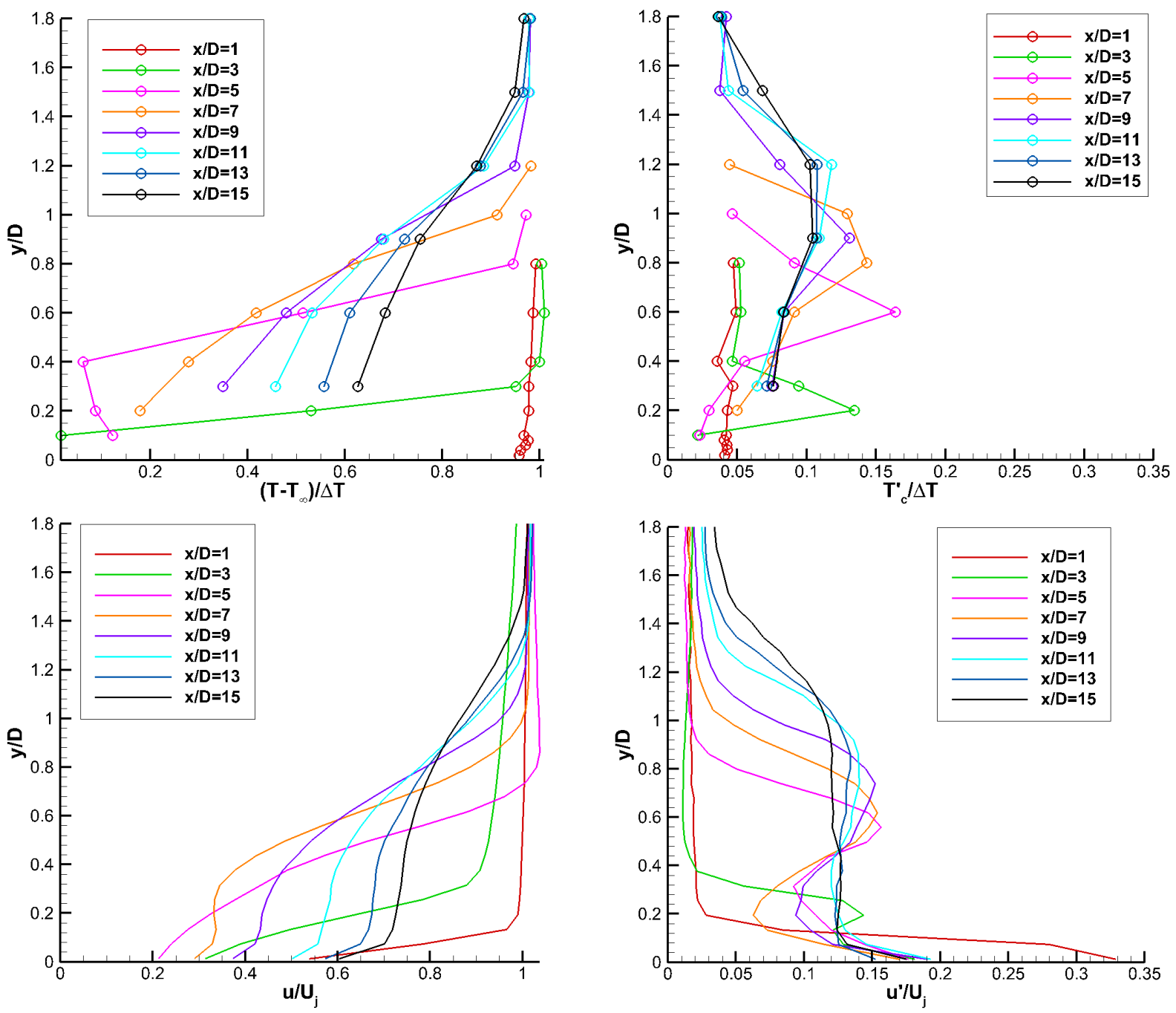

Figure 27: Normalized mean and rms temperature profiles measured via Raman scattering and PIV normalized velocity and turbulence profiles for Set Point 49, $\mathrm{Br}=1.0$.

\section{Film Effectiveness}

The average plate temperatures from the embedded thermocouples were used to compute a film effectiveness [Bogard \& Thole, 2006]:

$$
\eta=\frac{T_{\infty}-T_{A W}}{T_{\infty}-T_{c, \text { exit }}}
$$

Where $T_{\infty}$ is the exit gas temperature from the nozzle, $T_{A W}$ is the adiabatic wall temperature and $T_{c, e x t}$ is the injection cooling gas temperature at the exit port. It should be noted that the experimental configuration used here has several differences with typical experiments used for turbine film cooling characterization. Most notably, the installation of the nozzle and ramp, open to the ambient air in the AAPL, allows for several heat transfer mechanisms beyond the cooling provided by the injector flow, which result in cooling of all of the surface temperatures. In contrast, many typical turbine stage film cooling experiments are conducted in an enclosed insulated duct, where the heat transfer from the test article, apart from that done by the cooling stream(s), is significantly lower than that considered here. Further, $T_{A W}$ is defined here as the fluid temperature immediately above the surface to be cooled, and is not, in principle, the same quantity as the adiabatic wall temperature normally thought of in terms of the wall temperature in a compressible flow with no heat transfer allowed at the wall. With these qualifiers, the film cooling effectiveness was computed for all of the cases considered here, using the thermocouple readings along the top of the plate for $T_{A W}$. 
The efficiencies for all of the tested Set Points and blowing ratios are plotted in figure 28 overlaid on the model hardware. The transparent model enables visualizing the thermocouple located inside the nozzle lip. Note there was a bad thermocouple in the $\mathrm{Br}=1.0$ test run, $\left(3^{\text {rd }}\right.$ row from top on the right side) which was replaced at the end of the run. The injectant air temperature is measured inside the tube at approximately $355 \mathrm{~mm}$ below the top of the plate. The film effectiveness is plotted as a scatter plot where the color of the circle indicates the film cooling effectiveness per Equation 5 .

In the literature, the mass flux ratio (which is identical to the quantity $\mathrm{Br}$ used in this work) and momentum ratio, $\mathrm{I}_{\mathrm{r}}$, have been used extensively to compare film cooling concepts. In figure 29, the effect of $\mathrm{Br}$ and $\mathrm{Ir}$ on film effectiveness along the centerline of the hardware are presented where the $\mathrm{x}$-coordinate is normalized by the injector hole diameter and referenced to the trailing edge of the injector hole, $\mathrm{x}_{0}$. Each of the five subplots correspond to a fixed Set Point (nozzle exit condition). From prior published work, peak film effectiveness is expected near $\mathrm{Br}=0.5$, hence it is not surprising the film effectiveness for $\mathrm{Br}=0.5$ and $\mathrm{Br}=1.0$ are qualitatively similar at each Set Point. $\mathrm{A} \mathrm{Br}=2.0$ case was examined for the Set Point 23 nozzle exit condition which results in substantially lower film effectiveness than the $\mathrm{Br}=0.5$ and 1.0 cases, especially just downstream of the injector hole. $\mathrm{The} \mathrm{Br}=2.0$ case corresponds to $\mathrm{Ir}=2.27$. For $\mathrm{Ir}>0.8$, it is expected that the coolant flow will detach from the plate surface, and result in exactly the film effectiveness shown here.

The film effectiveness for all cases with $\mathrm{TR}=1.765$ and $\mathrm{Br}=1.0$ are shown in Figure 30a and all cases with $\mathrm{TR}=2.7$ and $\mathrm{Br}=1.0$ are shown in Figure 30b. Hence, these plots show the variation in film cooling effectiveness with all conditions held constant except for variation in jet Mach number (Mach 0.377 to 0.677 for Set Point 23 and 27, respectively and Mach 0.304 to 0.548 to 0.900 for Set Point 42, 46, and 49, respectively). It may be observed that as the jet Mach number increases, the film effectiveness decreases. Although not shown here, the same trend is observed for the $\mathrm{Br}=0.5$ cases.
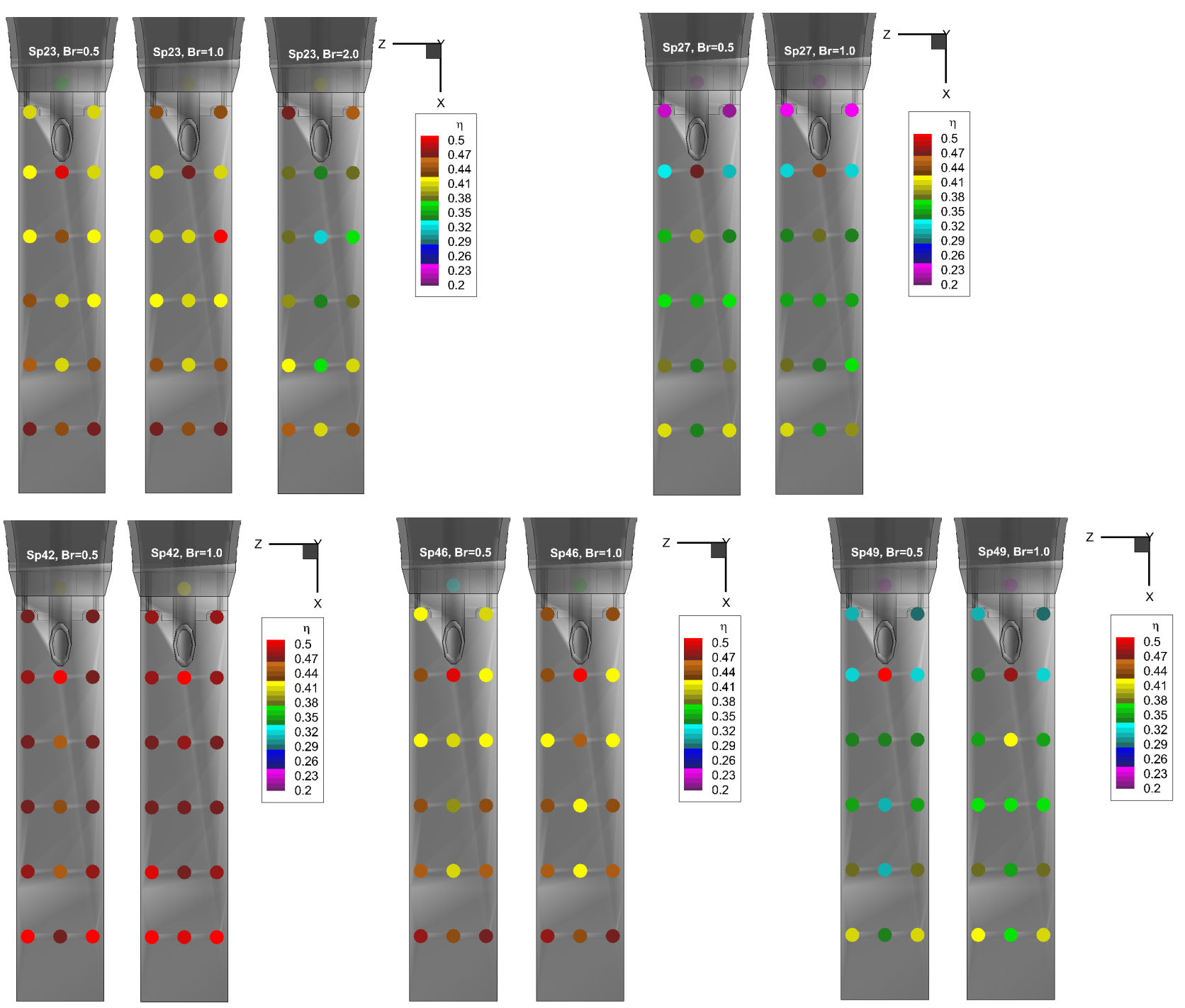

Figure 28: Film effectiveness measured via embedded thermocouples are plotted as the circle symbols, where the color of the symbol indicates the effectiveness value, $\eta$. 

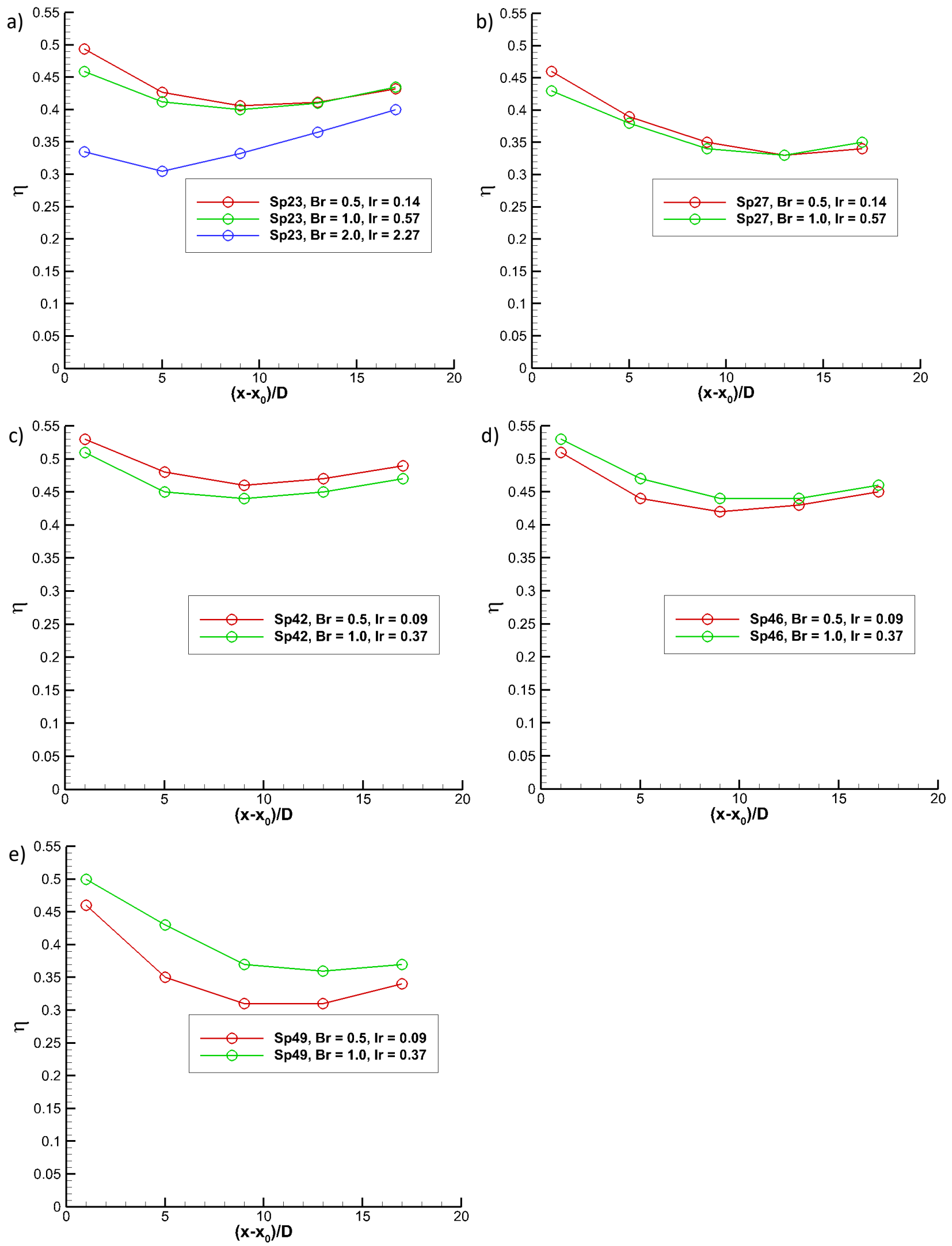

Figure 29: Centerline plots of the film effectiveness for all $\mathrm{Br}$ cases at Set Points a) 23, b) 27, c) 42, D) 46, e) 49. 

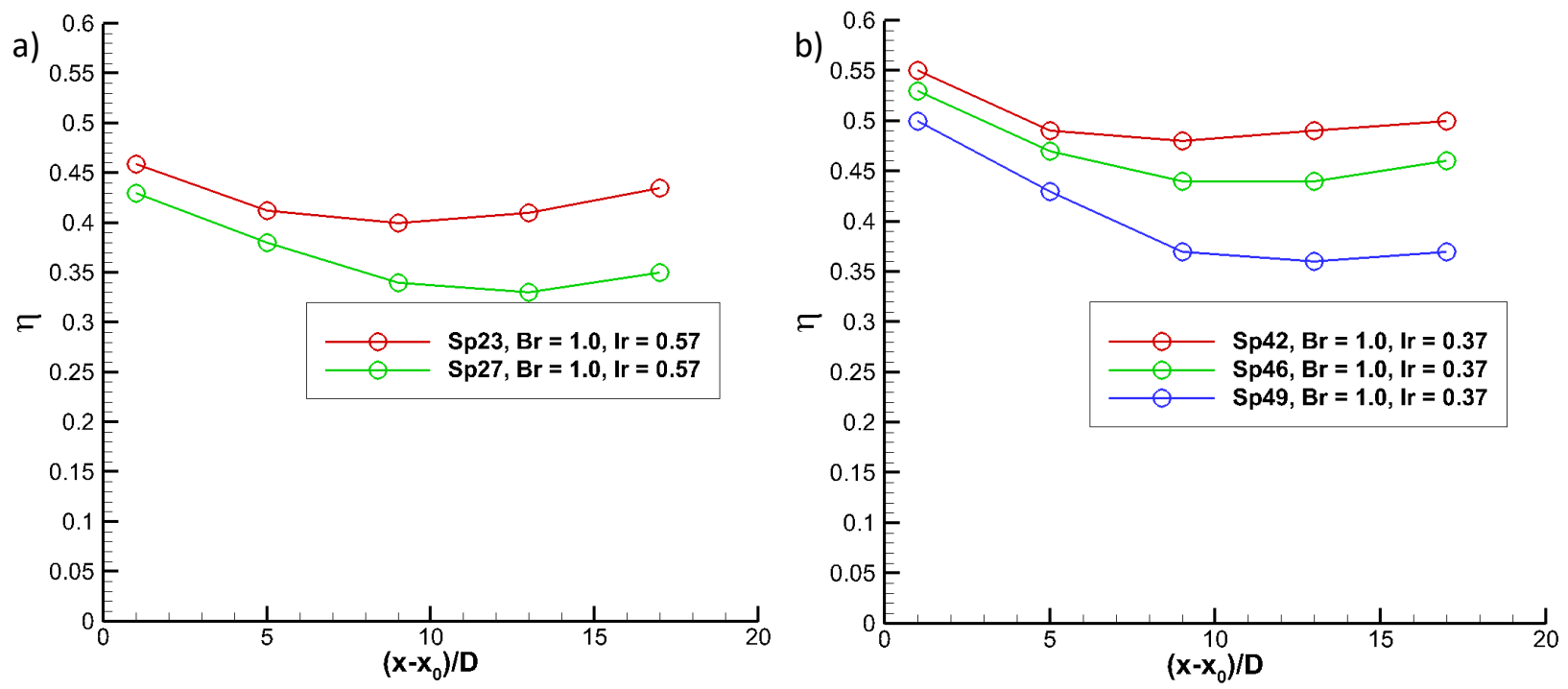

Figure 30: Centerline plots of film effectiveness for $\mathrm{Br}=1$, at: a) $\mathrm{TR}=1.765$ and b) $\mathrm{TR}=2.7$.

\section{Baseline CFD Analysis}

The focus of this paper is on the experimental measurements that were made in order to evaluate and improve CFD and not an extensive CFD investigation. However, in order to establish the current state-of-practice for such an experimental configuration, we present a set of CFD runs obtained using relatively standard Reynolds-averaged NavierStokes (RANS) modeling. CFD simulations of the experimental configuration were run using the Wind-US CFD code [Yoder 2016b], a general purpose CFD solver used extensively at NASA GRC for inlet, nozzle, and other propulsion flow simulations. Because of the RANS approach and the expected time-averaged symmetry in the spanwise direction, only half of the full configuration was simulated. The simulations were run in Reynolds-averaged Navier-Stokes (RANS) mode, using the Menter SST k- $\omega$ shear stress transport (SST) model [Menter 1992 and Menter 1994]. The turbulent Prandtl number, Prt, was set to 0.7 for these cases. The ratio of specific heats was set to 1.37 for all cases considered herein.

A structured computational grid having $26,000,000$ points across 29 zones was constructed using the gridgen/pointwise software [Pointwise 2013]. Grids were packed to solid surfaces such that the reference $y+$ corresponding to the first point off the wall did not exceed 1 using fully expanded nozzle conditions. The nozzle was modeled from the junction with the facility supply pipe. The injector tube was modeled for the full length of 40 injector tube diameters, as it was determined that this would be sufficient to provide fully developed turbulent flow in the tube before exiting over the deck surface. The far-field boundaries surrounding the nozzle/deck assembly were placed a sufficient distance away from the nozzle/deck region such that the far-field would have no influence on the flow near the nozzle deck. The outflow of the computational domain was placed approximately one deck length downstream of the trailing edge of the deck. A freestream Mach number of 0.05 was set to prevent any convergence difficulties. Previous simulations of jets exhausting into quiescent ambient [Georgiadis, 2006] indicate that a freestream flow of this speed would yield jet decay very similar to no freestream flow settings.

Most of the solid surfaces, including the interior of the nozzle, were set as adiabatic wall boundaries. As discussed previously, an array of thermocouples was installed on the deck to measure the local surface temperature in the experiments. For simplicity in these initial calculations, 17 thermocouple readings over the plate were averaged for each experimental Set Point, to apply a single temperature to the entire plate surface. The nozzle inflow condition was set to the stagnation pressure and temperature measured in the experiment. For the injector tube inflow, the stagnation pressure set at the inflow was iterated upon during a particular Set Point calculation, until the blowing ratio from the experiment for that Set Point was matched to within 1 percent.

Figures 31-34 show a comparison of experimental results with RANS calculations for the Set Point 23 nozzle flow, with blowing ratios of $0.5,1.0$, and 2.0, respectively. Axial velocities normalized by the jet exit velocity $\mathrm{U}_{\mathrm{j}}$ and nondimensionalized static temperature are presented along the centerline of the plate. Following the streamwise PIV contours shown in Figure 17, as the blowing ratio is increased the injector flow transitions from more of a film cooling stream to more of an inclined jet-in-crossflow. The agreement of the CFD with experiment for both velocities and temperatures is not close at $\mathrm{BR}=0.5$, but improves as the blowing ratio increases to 2.0. Figure 34 shows an expanded comparison for the Set Point 23, BR=1.0 from the nozzle deck surface through the shear layer formed by the outer part 
of the nozzle flow mixing with the ambient. The qualitative agreement of data with CFD is reasonable for the outer shear later, away from the deck surface, with the RANS solution indicating somewhat slower mixing than the data. The ambient flow in the CFD solution is Mach 0.05 , compared to the nearly static flow $(<2 \mathrm{~m} / \mathrm{s})$ in the experimental case. The CFD velocity profiles also exhibit the same slowdown in the freestream velocity above the injection cooling hole at $\mathrm{x} / \mathrm{D}=3$ observed in the PIV data.
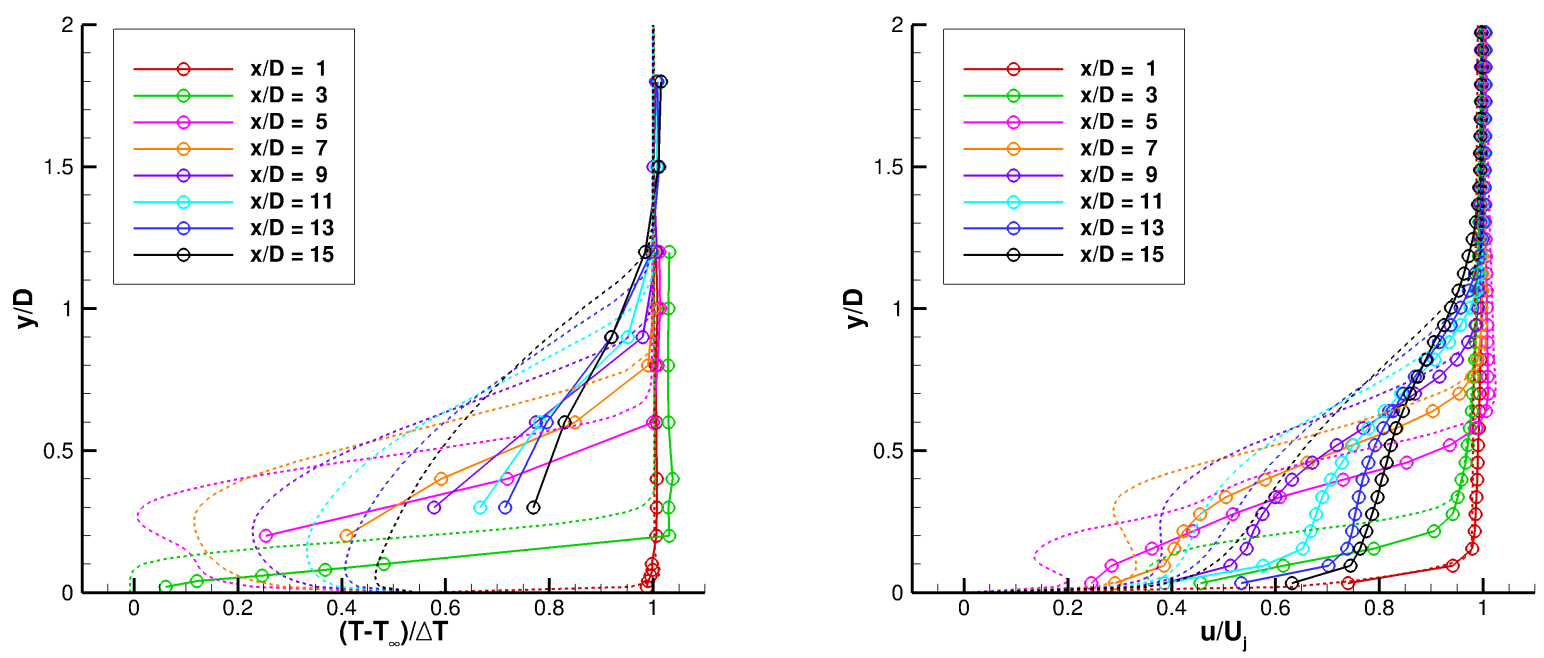

Figure 31: Comparison of RANS CFD (dashed lines) to the Raman temperature and PIV velocity measurements for the Set Point 23, $\mathrm{Br}=0.5$ case.
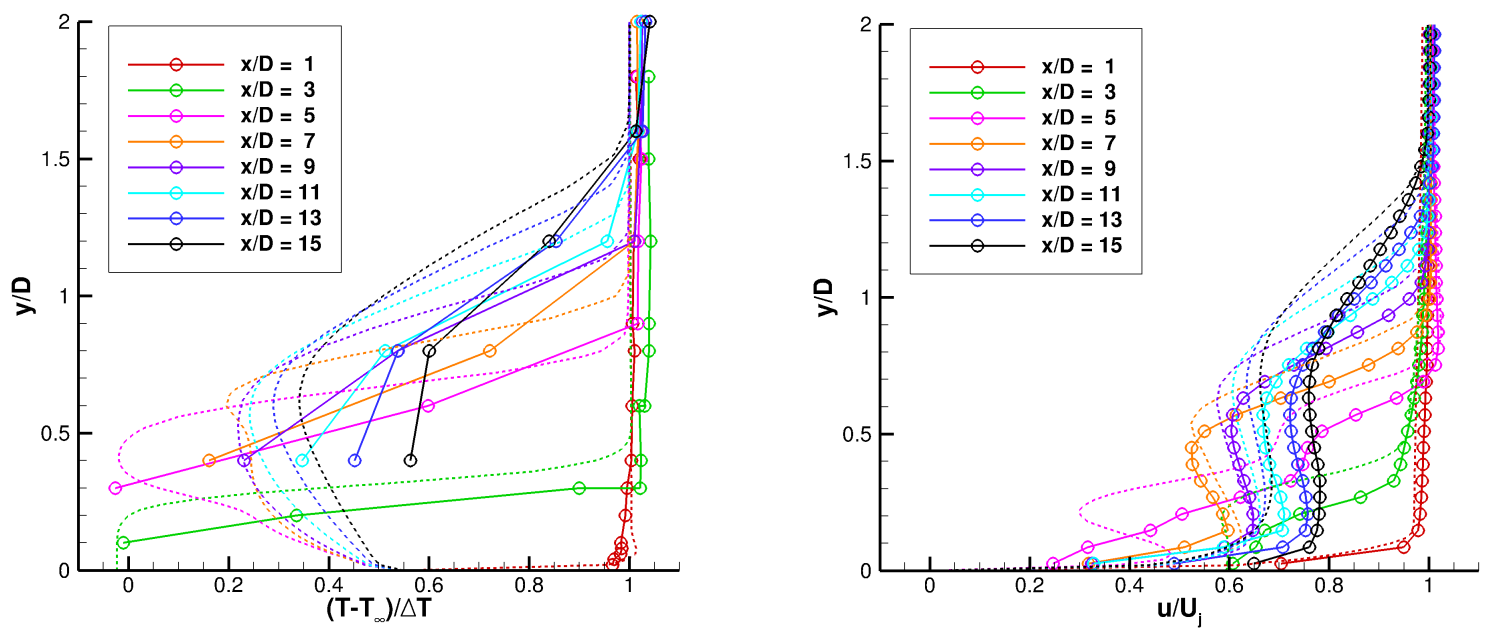

Figure 32: Comparison of RANS CFD (dashed lines) to the Raman temperature and PIV velocity measurements for the Set Point 23, $\mathrm{Br}=1.0$ case. 

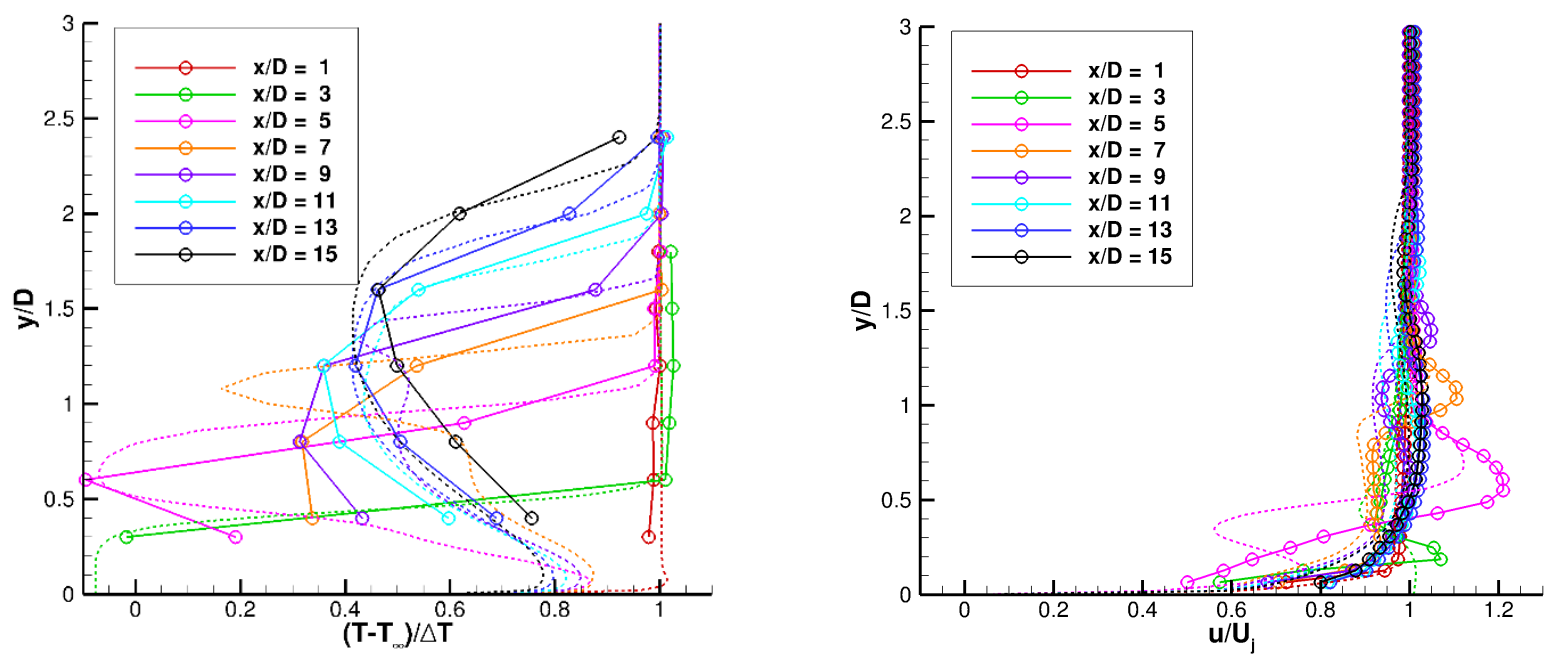

Figure 33: Comparison of RANS CFD (dashed lines) to the Raman temperature and PIV velocity measurements for the Set Point 23, $\mathrm{Br}=2.0$ case.

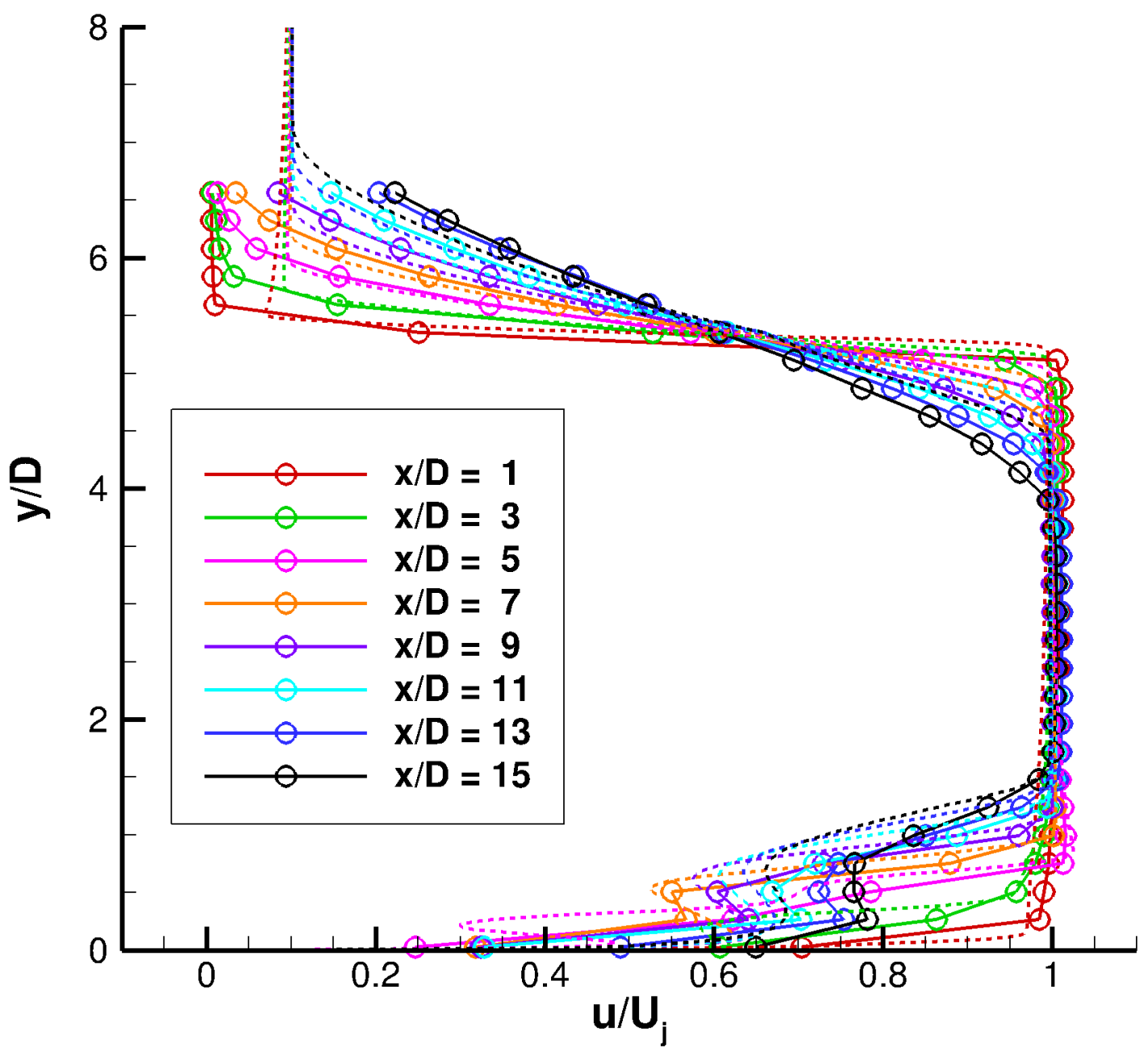

Figure 34: Full span comparison of RANS CFD (dashed lines) showing shear layer on the top of the jet and the injected cooling flow on the plate for the Set Point 23, $\mathrm{Br}=1.0$ case. 
Figures 35-38 provide comparison of experimental results and RANS calculations for velocities and temperatures near the plate for three of the higher temperature ratio nozzle flow cases, Set Point 46 with a blowing ratio of 0.5 and Set Point 49 with blowing ratios of 0.5 and 1.0. While Set Point 46 is at a higher temperature and slightly higher Mach number than Set Point 23 and Set Point 49 is at both a higher temperature and higher Mach number than Set Point 23, the trends of experiment-to-CFD comparison are similar. In particular, the RANS calculations indicate slower mixing of the cold injector flow with the hot nozzle exhaust. For Set Point 49, Br=0.5, Figure 38 shows a comparison analogous to that of Figure 34, for axial velocities from the deck surface through the shear layer formed from the nozzle exhaust with the ambient. The agreement is somewhat closer for Set Point 49 than Set Point 23, which is likely due to compressibility effects reducing the turbulent mixing rate for the higher Mach number case [Yoder et al., 2015].
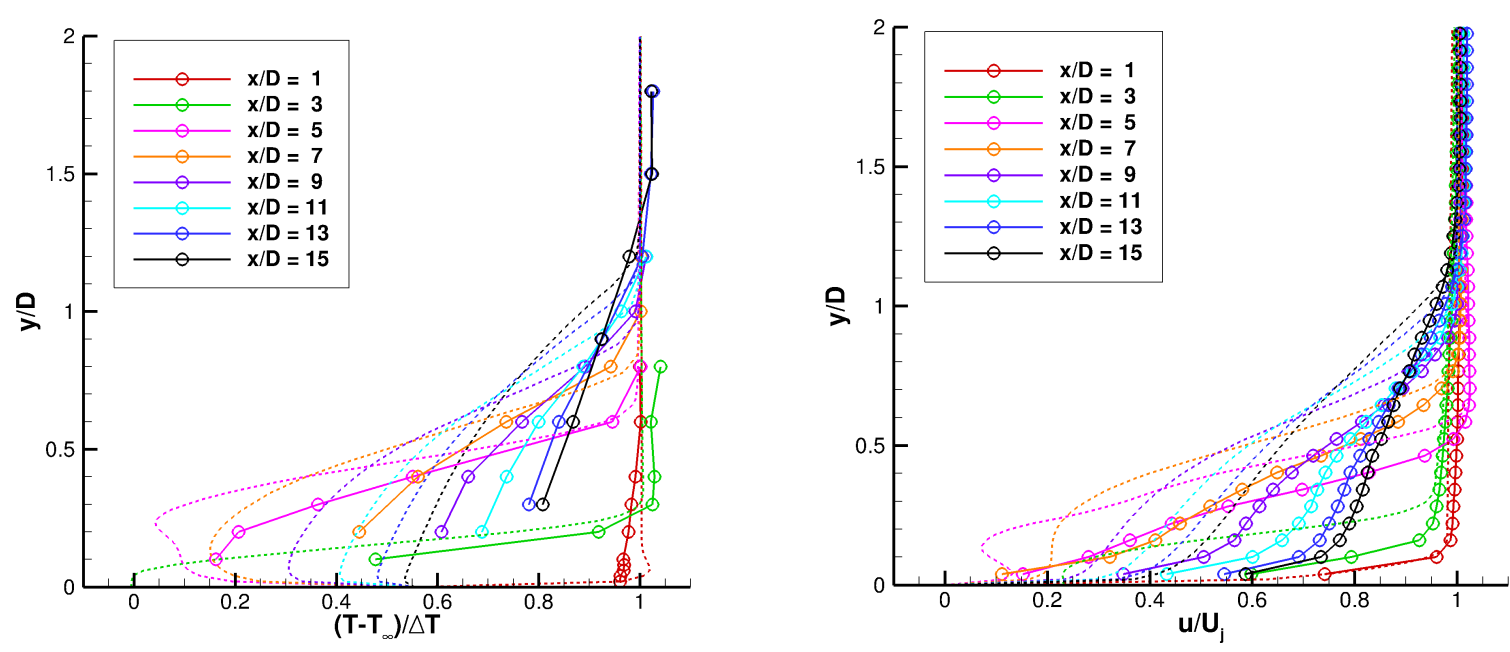

Figure 35: Comparison of RANS CFD (dashed lines) to the Raman temperature and PIV velocity measurements for the Set Point $46, \mathrm{Br}=0.5$ case.
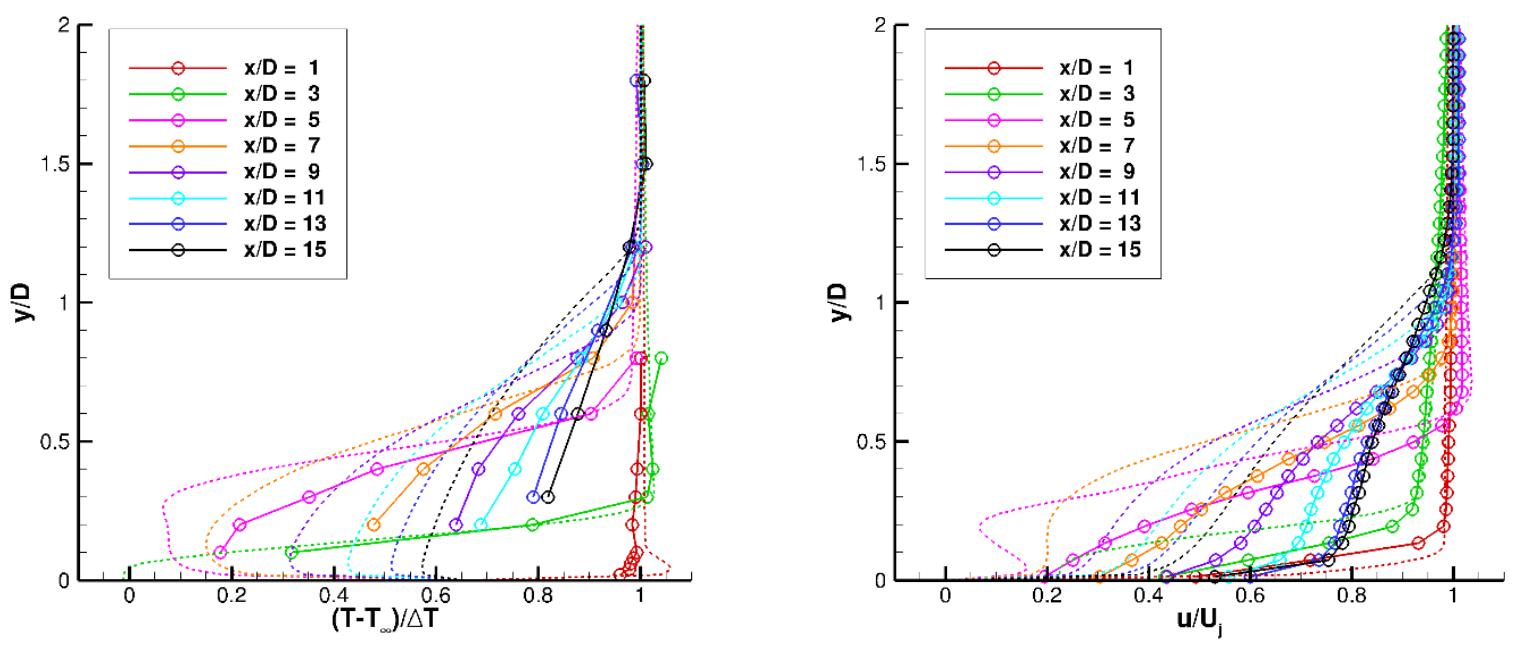

Figure 36: Comparison of RANS CFD (dashed lines) to the Raman temperature and PIV velocity measurements for the Set Point 49, $\mathrm{Br}=0.5$ case. 

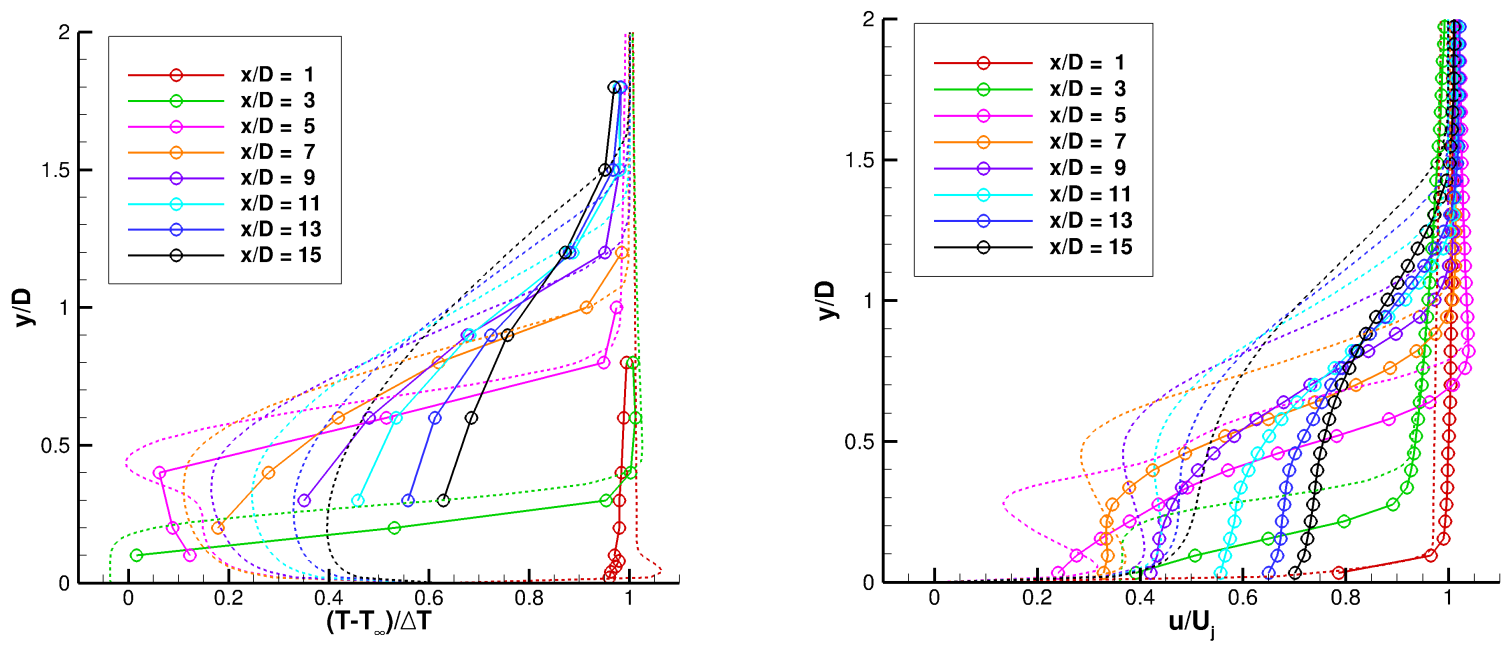

Figure 37: Comparison of RANS CFD (dashed lines) to the Raman temperature and PIV velocity measurements for the Set Point $49, \mathrm{Br}=1.0$ case.

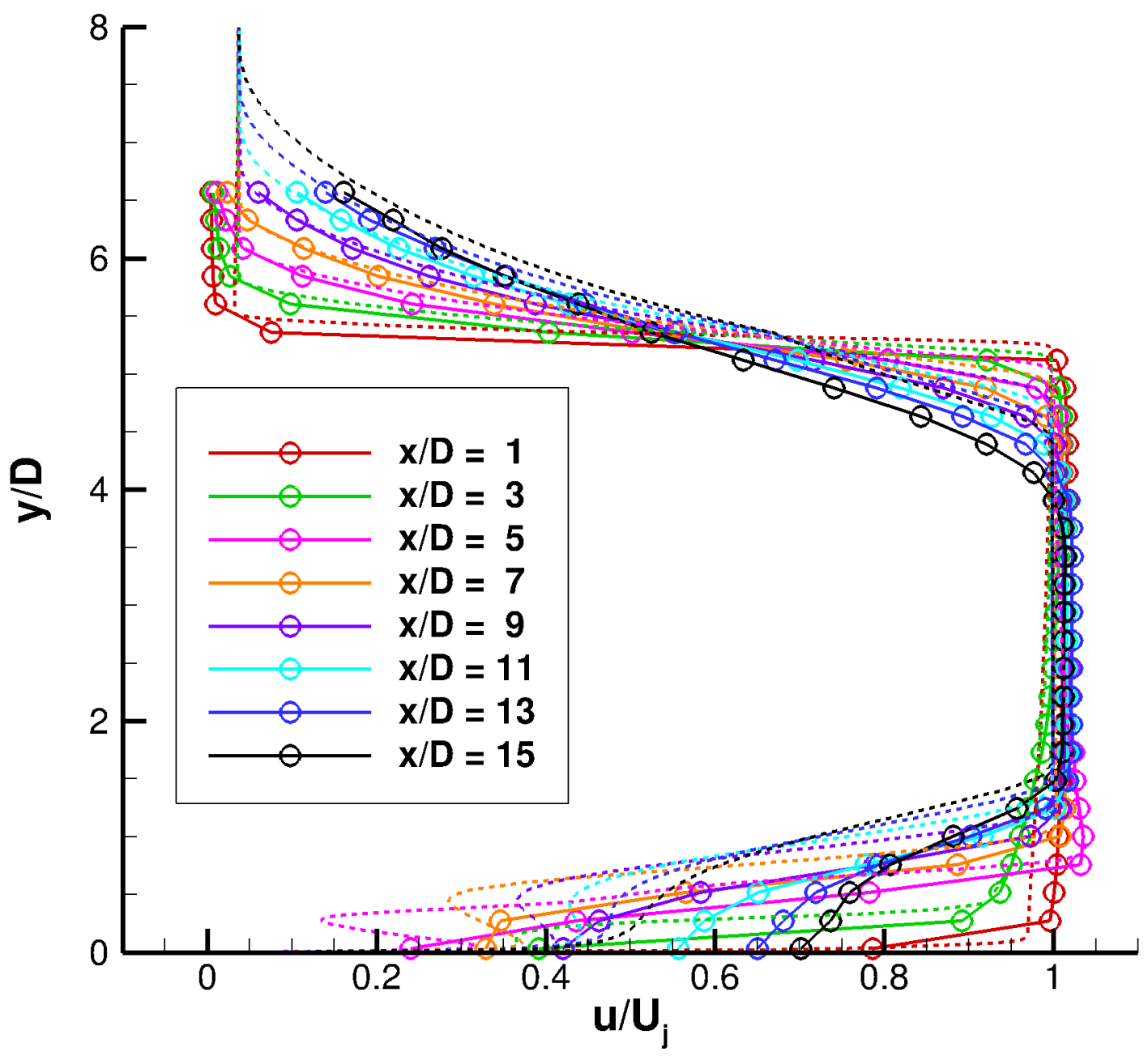

Figure 38: Full span comparison of RANS CFD (dashed lines) showing shear layer on the top of the jet and the injected cooling flow on the plate for the Set Point $49, \mathrm{Br}=1.0$ case.

Overall, the RANS results provided here are what is expected for a standard RANS approach employing an eddy viscosity turbulence model. In particular, the slower mixing of the CFD calculations relative to the data, is due to the inability of RANS to replicate the realistic turbulent state of the injector flow breaking up when interacting with the hot 
nozzle exhaust. Future CFD efforts will likely pursue more sophisticated RANS modeling, including possibly an explicit algebraic stress model and a variable turbulent Prandtl number model [Yoder, 2016a] for the turbulent heat flux. However, it is likely that a turbulence resolving method, such as large-eddy simulation (LES) will be required to more accurately replicate the injector flow problem investigated here.

\section{Conclusions}

A film cooling experiment was conducted in order to obtain high fidelity turbulent flow data for CFD model evaluation and development. The experiment utilized the heated air from a $68.07 \mathrm{~mm}$ square nozzle blowing over a flat plate equipped with a single cooling hole inclined at $30^{\circ}$ from the plate surface and primary nozzle flow direction. Mach numbers of the heated flow varying from 0.376 to 0.9 , temperature ratios of 1.7 and 2.7 and blowing ratios of 0.5 to 2.0 were investigated in the test matrix. Rotational Raman temperature measurements were used to acquire mean and rms temperature; PIV measurements in the vicinity of the single cooling hole were used to acquire mean and rms velocity measurements and thereby characterize the turbulent aerothermal state. While PIV has been used extensively in recent years for a number of turbulent flow problems, in order to obtain mean and rms velocities for turbulence model assessment and improvement efforts, there is a dearth of data available in the literature for mean and rms temperatures. The data acquired here is a unique contribution where both velocities and temperatures were measured in a unit flow problem representative of more complex engineering applications in aeropropulsion components.

In addition to flowfield measurements, thermocouples were embedded in the plate surface to record the surface temperatures and provide estimates of the film effectiveness. The Raman temperature data demonstrated rms errors down to $<3 \%$ in quiescent air at room temperature. A correction of the inherent rms variations in the Raman based temperature measurements was applied to the data. Velocity and turbulence intensity profiles across the shear layers in the injected air were compared with the rms temperature measurements. In most cases the peak fluctuations in velocity and temperature occurred at the same height above the plate. In a few cases the rms temperature peaked higher above the plate than the peak turbulence across the shear layer.

The experimental data were compared with RANS predictions of the cooling flow, employing a computational approach that may be considered a standard engineering approach today. The RANS predictions, employing a commonly used two-equation k- $\omega$ turbulence model, constant turbulent Prandtl number, and constant wall temperature boundary conditions, generally showed a much lower degree of mixing of the injected flow with the heated ambient flow stream. The RANS prediction of the heated jet shear layer mixing with the ambient air, away from the primary interaction region, was in good agreement with the PIV velocity field measurements.

The brief comparison of RANS CFD with the data presented here illustrates the depth and breadth of the data acquired during this investigation. The velocity and temperature data on this cooling flow is a novel, high quality asset for the assessment of current turbulent CFD models and for the development of new approaches. The RANS results presented here exhibit the inability of current turbulence modeling approaches to accurately replicate momentum mixing and especially thermal mixing. A more sophisticated RANS approach, employing a nonlinear eddy viscosity approach and/or a capability beyond constant turbulent Prandtl number modeling, perhaps may incrementally improve the agreement with data. However, it is likely that an approach which resolves most of the key turbulent flow region, i.e. large-eddy simulation (LES) or hybrid RANS-LES, will be necessary to more accurately capture the complex aerothermal state occurring in the flow problem under investigation.

Although the Raman thermometry diagnostic was able to capture the temperature gradients in the flow with good resolution by orienting the probe volume's narrow dimension to be perpendicular to the plate and hence the gradients, a smaller probe volume size would improve the system performance in a wider class of flows. The spatial resolution of the diagnostic can be improved by using different lenses and a cladding free fiber optic bundle, yielding a reduction in the probe volume length from the $6 \mathrm{~mm}$ length used in this work down to $1.5 \mathrm{~mm}$, with an actual 2x increase in signal intensity.

\section{Acknowledgements}

This work was supported by the Transformative Tools and Technology Project of the Revolutionary Computational Aerosciences (RCA) Program. The Authors would also like to recognize Garrett Clayo for his assistance in the design and fabrication of the optical mounting system.

\section{Addendum Statement}

The entire data set of Raman temperature data and PIV velocity data covering the complete test matrix in Table 1 is available from the NASA GRC STI office upon request. 


\section{Reference List}

1) Bogard, D. G., Thole, K. A., 2006, Gas Turbine Film Cooling, J. of Propulsion and Power, Vol. 21, No. 6, pp. 1-22.

2) Smith, S. and M. Mungal, 1998, Mixing, Structure and Scaling of the Jet in Crossflow, J. of Fluid Mechanics 357, pp.83-122.

3) Bergeles, G., A. Gosman, and B. Launder, 1977 Near-Field Character of a Jet Discharged through a Wall at $30^{\circ}$ to a Mainstream, AIAA Journal, Vol. 15 No.4, pp.499-504.

4) Baldauf, S. M., Schulz, A., and Wittig, S., 2001, High-Resolution Measurements of Local Effectiveness from Discrete Hole Film Cooling, J. of Turbomachinery, Vol. 123, pp. 758-765.

5) Mee, D.J., Ireland, P.T., Bather, S., 1999, Measurement of the temperature field downstream of simulated leadingedge film-cooling holes, Exp in Fluids, Vol 27, No. 3, pp. 273-283.

6) Andreopoulos, J. and Rodi, W., 1984, Experimental Investigation of Jets in a Crossflow. J. of Fluid Mechanics 138, 93-127.

7) Haldeman, C. W.; Mathison, R. M.; Dunn, M. G.; Southworth, S.; Harral, J. W.; Heitland, G., 2006, Aerodynamic and Heat Flux Measurements in a Single Stage Fully Cooled Turbine- Part I: Experimental Approach; ASME Paper GT2006-90966.

8) Poinsatte, P. E., Heidemann, J. E., Thurman, D. R., 2008, Heat Transfer Measurements for a Film Cooled Turbine Vane Cascade, NASA/TM-2008-215485, GT2008-50651, Gas Turbine Technical Congress and Exposition (Turbo Expo 2008); 9-13 Jun. 2008; Berlin; Germany.

9) Shyam, V., Thurman, D., Poinsatte, P., Ameri, A., Eichele, P., 2014, Long Hole Film Cooling Dataset for CFD Development - Flow and Film Effectiveness, 50th AIAA/ASME/SAE/ASEE Joint Propulsion Conference, AIAA Propulsion and Energy Forum, AIAA 2014-3522.

10) Yoder, D. A., 2016a, Comparison of Turbulent Thermal Diffusivity and Scalar Variance Models, 54th AIAA Aerospace Sciences Meeting, AIAA SciTech Forum, (AIAA 2016-1561) https://doi.org/10.2514/6.2016-1561

11) Bridges, J. and Wernet, M.P., 2003, Measurements of the Aeroacoustic Sound Source in Hot Jets, AIAA-2003-3130, 9th AIAA/CEAS Aeroacoustics Conference and Exhibit, https://doi.org/10.2514/6.2003-3130

12) Panda, J., Seasholtz, R. G., Elam, K. A., 2005, Investigation of Noise Sources in High-Speed Jets Via Correlation Measurements, J. Fluid Mechanics, 537 pp. 349-385.

13) Mielke, Amy F., Elam, Kristie A., 2009, Dynamic Measurement of Temperature, Velocity, and Density in Hot Jets Using Rayleigh Scattering, Exp in Fluids, 47:6, pp. 673-688.

14) Cutler, A. D., Magnotti, G., Cantu, L., Gallu, E., Rockwell, R. and Goyne, C., 2014, Dual-Pump Coherent AntiStokes Raman Spectroscopy Measurements in a Dual-Mode Scramjet, J. Propulsion and Power, Vol. 30, No. 3, May-June 2014, pp.539-549. DOI: 10.2514/1.B34964.

15) Tedder, S., P. Danehy, G. Magnotti, and A. Cutler, 2009, CARS temperature measurements in a combustor-heated mach 1.6 jet, AIAA-2009-0524, $47^{\text {th }}$ Aerospace Science Meeting, Orlando, Florida

16) Kuehner, J. P., Tessier, A. F., Kisoma, A., Flittner, J. G., McErlean, M. R., 2010, Measurements of Mean and Fluctuating Temperature in an Underexpanded Jet Using Electrostrictive Laser-Induced Gratings, Exp in Fluids $\mathbf{4 8}$ pp. 421-430.

17) Ajrouche, H., Vervisch, P., Lo, A., Cessou, A., 2014, 1D single-shot thermometry in flames by Spontaneous Raman Scattering through a fast electro-optical shutter, 17th International Symposium on Applications of Laser Techniques to Fluid Mechanics Lisbon, Portugal

18) Maté, G. Tejeda, and S. Montero, 1998, Raman spectroscopy of supersonic jets of $\mathrm{CO}_{2}$ : Density, condensation, and translational, rotational, and vibrational temperatures, J. Chem. Phys. 108, 2676 
19) Locke, R. J., Wernet, M. P., Anderson, R. C., 2017, Rotational Raman-Based Temperature Measurements in a HighVelocity Turbulent Jet, Meas. Sci. Technol., https://doi.org/10.1088/1361-6501/aa934d, also published as NASA/TM-2017-219504

20) Yoder, D.A., DeBonis, J.R., and Georgiadis, N.J., , 2015, Modeling of Turbulent Free Shear Layer Flows, Computers \& Fluids, Vo. 117, pp. 212-232.

21) Reynolds, A.J., Turbulent Flows in Engineering. John Wiley and Sons, New York, 1974.

22) Kays, W.M., Turbulent Prantdl Number - Where Are We?, ASME Trans., Vol. 116, May 1994.

23) Wernet, M. P., Wroblewski, A. C., Locke, R. J., 2016, A Dual-Plane PIV Study of Turbulent Heat Transfer Flows, NASA/TM-2016-219074.

24) DeBonis, J. R., 2017, Prediction of Turbulent Temperature Fluctuations in Hot Jets, 23rd AIAA Computational Fluid Dynamics Conference, AIAA AVIATION Forum, (AIAA 2017-3610) https://doi.org/10.2514/6.2017-3610

25) Bridges, J. and Wernet, M. P., 2011, The NASA Subsonic Jet Particle Image Velocimetry (PIV) Dataset, NASA Technical Memorandum, NASA/TM-2011-216807

26) Ferraro, J. R., and Nakamoto, K., 1994, Introduction to Raman Spectroscopy, Academic Press, San Diego, CA

27) Wernet M. P. and Hadley, J. A., 2016, A high temperature seeding technique for particle image velocimetry, Meas. Sci. Technol. 27 125201, https://doi.org/10.1088/0957-0233/27/12/125201

28) Melling A., 1997, Tracer particles and seeding for particle image velocimetry. Meas. Sci. Technol. 8:1406-1416.

29) Wernet M.P., 2005, Symmetric phase only filtering: a new paradigm for DPIV data processing. Meas. Sci. Technol. 16:601-618.

30) Taylor, J.R., 1982, An introduction to error analysis, University Science Books, Oxford University Press, Mill Valley, pp. 142-144.

31) Menter, F. R., 1992, Improved Two Equation k- $\varepsilon$ Turbulence Models for Aerodynamic Flows, NASA/TM 103975, October.

32) Menter, F. R., 1994, Two Equation Eddy-Viscosity Turbulence Models for Engineering Applications, AIAA Journal, Vol. 32, No. 8, pp. 1598-1605.

33) Yoder, D.A., 2016b, Wind-US User's Guide - Version 4.0, NASA TM 2016-219145, Sept.

34) Pointwise ${ }^{\circledR}$ [software package], Ver. 17.1 Release 4, Pointwise, Inc., Fort Worth, TX, 2013.

35) Georgiadis, N.J., Yoder, D.A., and Engblom, W.A., 2006, Evaluation of Modified Two-Equation Turbulence Models for Jet Flow Predictions, AIAA Journal, Vol 44, No. 12, pp. 3107-3114. 